Research Article

\title{
Combined Effect of Compaction Methods and Loading Conditions on the Deformation Behaviour of Unbound Granular Material
}

\author{
Jiaolong Ren $\mathbb{D}^{1},{ }^{1}$ Di Li $\mathbb{D},{ }^{2}$ and Siyuan Wang ${ }^{1}$ \\ ${ }^{1}$ School of Civil and Architectural Engineering, Shandong University of Technology, Zibo 255000, China \\ ${ }^{2}$ State Key Laboratory Geohazard Prevention and Geoenvironment Protection, Chengdu University of Technology, \\ Chengdu 610059, China
}

Correspondence should be addressed to Jiaolong Ren; worjl@126.com and Di Li; lidi2014@cdut.edu.cn

Received 18 February 2020; Revised 29 June 2020; Accepted 1 July 2020; Published 22 July 2020

Academic Editor: Fan Gu

Copyright (C) 2020 Jiaolong Ren et al. This is an open access article distributed under the Creative Commons Attribution License, which permits unrestricted use, distribution, and reproduction in any medium, provided the original work is properly cited.

Unbound granular material is an important construction material that is used for flexible pavement. As one of the most important indices used for describing the properties of unbound granular material, the deformation characteristic is significantly influenced by the compaction method used. However, the effects of the compaction method on the deformation behaviour are neglected in the existing studies. Hence, we investigate the deformation characteristics of unbound granular material produced by the vertical vibration compaction method (VVCM) and the modified Proctor compaction method (MPCM) via repeated triaxial load tests and reveal the effect of loading conditions and aggregate gradations. The results show that (a) the deformation of unbound granular material decreases as the stress level and confining pressure are increased; (b) the deformation resistance of unbound granular material produced by the VVCM is superior to that produced by the MPCM; (c) the difference of deformation resistance arising between using the VVCM and MPCM decreases as confining pressure increases and is not significant with changes in the stress level; (d) the extent of various factors on deformation characteristics from greatest to least is as follows: stress level > aggregate gradation > compaction method > confining pressure; and (e) increasing the content of coarse aggregates is conducive to enhancing the deformation resistance of unbound granular material, particularly for the VVCM. Finally, a simple approach for modelling and predicting deformation is established.

\section{Introduction}

It is well known that flexible pavements with composite bases have desirable structural and functional capacities [1-3]. Unbound granular material (e.g., graded crushed stone) is an important construction material used in the base and subbase layers of flexible pavement; its advantages include the ability to provide structural support for asphalt concrete layers and an adequate response to traffic loads at a relatively low cost [4-6]. The fatigue cracking and rutting development of asphalt concrete layers are associated with the deformation characteristics of unbound granular material layers $[7,8]$; these characteristics are predicted and controlled typically during pavement design $[9,10]$. Hence, investigating the deformation characteristics of unbound granular material for flexible pavement structures is beneficial $[11,12]$.

Rahman and Erlingsson $[6,13]$ investigated the effect of moisture on the resilient deformation behaviour of unbound granular material and established the corresponding prediction model. Alnedawi et al. [14-16] analyzed the effect of loading conditions (e.g., loading frequencies and vertical stress rest period) on the deformation behaviour of unbound granular material and built a prediction model of permanent deformation by utilizing a neural network. Osouli et al. [17] revealed the effect of aggregate fines on the deformation behaviour of unbound granular material. $\mathrm{Gu}$ et al. [9] characterized the permanent deformation properties of unbound granular material from the point of view of Pavement ME Design. Xiao et al. 
[12] carried out a shakedown analysis of the deformation of unbound granular material, as based on moving wheel loads. Xu et al. [18] put forward the control standard for the deformation performance of unbound granular material. Lu et al. [19] studied the dynamic deformation of road high liquid limit subgrade soil. Saberian et al. [20] investigated the permanent deformation of unbound granular materials with crumb rubber and crushed glass. Zhang et al. [21-23] established a series of improved prediction models to evaluate the permanent deformation and resilient modulus for highway subgrade soils, and revealed the effect of compaction, matric suction, and traffic loads. These require a proper understanding of the deformation behaviour under various influencing factors such as loading conditions (e.g., loading stress, loading time, and confining pressure), aggregate gradation, and compaction density.

Among these factors, the compaction density, which has a direct relationship with the compaction method, is regarded as one of the most important indices of pavement properties of unbound granular material [13, 24-26]. In the Chinese specification "Technical Guidelines for Construction of Highway Roadbases (JTG/T F20-2015)" and "Test Methods of Soils for Highway Engineering (JTG E40-2007)," there are two types of compaction methods available for producing experimental samples of unbound granular material: the vertical vibration compaction method (VVCM) and the modified Proctor compaction method (MPCM). Both compaction methods are permitted during material design in China; these methods significantly influence the performance of unbound granular materials.

Existing studies [26-29] have proven that the compaction density and mechanical properties of unbound granular material produced by the VVCM perform closely to what is observed in the field, which is superior to the MPCM because the VVCM results in a similar compaction status to what is observed on construction sites. However, there is little analysis about the effect of compaction methods on the deformation behaviour of unbound granular material in the existing literature. Hence, it is necessary to investigate the deformation characteristics of unbound granular material produced by different compaction methods and reveal the effects of loading conditions (e.g., deviator stresses and confining presses) and aggregate gradations; this is the purpose of this study.

\section{Objectives}

The objective of this study is to investigate the deformation characteristics of unbound granular material produced by different compaction methods. Specifically, the following two cases are considered:

(a) The effect of various compaction methods on the deformation behaviour of unbound granular material

(b) The sensitivity of loading conditions (e.g., deviator stresses and confining presses) and aggregate gradations to the effect of compaction methods
This is achieved by running repeated triaxial load tests on unbound granular material produced by the VVTM and MPCM for a range of loading conditions and aggregate gradations. All tests in accordance with Chinese specification "Technical Guidelines for Construction of Highway Roadbases (JTG/T F20-2015)" and "Test Methods of Materials Stabilized with Inorganic Binders for Highway Engineering (JTG E51-2009)" are carried out on these unbound granular materials; the results are, then, compared. The method specified in the JTG/T F20-2015 and JTG E51-2009 is used to capture the axial strain with respect to different deviator stresses and confining presses. A simple approach for modelling the deformation prediction is also established.

\section{Materials and Methods}

3.1. Materials. The unbound granular material is composed of four types of aggregates with different size ranges: $\quad 31.5-19 \mathrm{~mm}, \quad 19-9.5 \mathrm{~mm}, \quad 9.5-4.75 \mathrm{~mm}$, and $0-4.75 \mathrm{~mm}$. The aggregates are obtained from Shaanxi province of China, and their technical properties are shown in Table 1.

Two types of aggregate gradations are selected in this study, as shown in Table 2. The strong skeleton gradation is proposed in our previous research [30] via the optimization of the aggregate structure. The specification gradation is the midvalue of the standard aggregate gradation provided by the Chinese specification "Technical Guidelines for Construction of Highway Roadbases (JTG/T F20-2015)".

3.2. Compaction Method. In this study, the VVCM and MPCM are both adopted to produce the unbound granular material samples according to the Chinese specification "Test Methods of Materials Stabilized with Inorganic Binders for Highway Engineering (JTG E51-2009)". The processes of VVCM and MPCM are as follows.

\subsection{1. $V V C M$}

Step 1: the aggregates and water are mixed according to the target moisture content.

Step 2: the samples $(\Phi 152 \mathrm{~mm} \times h 120 \mathrm{~mm})$ are prepared using a vertical vibration compactor with an excitation force of $6800 \mathrm{~N}$. The vibration duration and frequency are $70 \mathrm{~s}$ and $30 \mathrm{~Hz}$, respectively.

Step 3: the dry density of the sample prepared in Step 2 is measured.

Step 4: Steps 1-3 are repeated, and the optimum moisture content and the maximal dry density are determined.

Step 5: the final cylindrical samples $(\Phi 100 \mathrm{~mm} \times$ $h 200 \mathrm{~mm}$ ) are prepared using a vertical vibration compactor using the optimum moisture content. The vibration duration and frequency are $100 \mathrm{~s}$ and $30 \mathrm{~Hz}$, respectively. 
TABLE 1: Technical properties of aggregates.

\begin{tabular}{|c|c|c|c|c|c|c|c|c|c|}
\hline $\begin{array}{l}\text { Aggregate } \\
\text { size }(\mathrm{mm})\end{array}$ & $\begin{array}{c}\text { Bulk volume } \\
\text { relative } \\
\text { density } \\
\left(\mathrm{g} / \mathrm{cm}^{3}\right)\end{array}$ & $\begin{array}{c}\text { Water } \\
\text { absorption } \\
(\%)\end{array}$ & $\begin{array}{l}\text { Crushing } \\
\text { value (\%) }\end{array}$ & $\begin{array}{c}\text { Los Angeles } \\
\text { abrasion } \\
(\%)\end{array}$ & $\begin{array}{l}\text { Content of } \\
\text { needle-like } \\
\text { (\%) }\end{array}$ & $\begin{array}{c}\text { Firmness } \\
(\%)\end{array}$ & $\begin{array}{c}\text { Sand } \\
\text { equivalent } \\
(\%)\end{array}$ & $\begin{array}{c}\text { Liquid } \\
\text { limit (\%) }\end{array}$ & $\begin{array}{l}\text { Plasticity } \\
\text { index (\%) }\end{array}$ \\
\hline $31.5 \sim 19$ & 2.725 & 0.3 & - & 19.4 & 6.6 & 5.4 & - & - & - \\
\hline $19 \sim 9.5$ & 2.721 & 0.6 & 19.5 & 20.5 & 8.4 & 5.8 & - & - & - \\
\hline $9.5 \sim 4.75$ & 2.633 & 0.6 & - & 20.9 & 5.8 & 6.3 & - & - & - \\
\hline$<4.75$ & 2.645 & 0.7 & - & - & - & 6.2 & 71.5 & 17 & 2.8 \\
\hline
\end{tabular}

TABLE 2: Aggregate gradation.

\begin{tabular}{lcc}
\hline Diameter $(\mathrm{mm})$ & \multicolumn{2}{c}{ Pass percent $(\%)$} \\
& Strong skeleton gradation & $\begin{array}{c}\text { Specification } \\
\text { gradation }\end{array}$ \\
\hline 31.5 & 100 & 100 \\
19 & 64 & 84 \\
16 & 58 & 76 \\
13.2 & 52 & 68.5 \\
9.5 & 46 & 56.5 \\
4.75 & 36 & 35 \\
2.36 & 28 & 23.5 \\
1.18 & 23 & 16 \\
0.6 & 19 & 11 \\
0.3 & 15 & 7.5 \\
0.15 & 11 & 5 \\
0.075 & 8 & 3.5 \\
\hline
\end{tabular}

\subsection{2. $M P C M$}

Step 1: the aggregates and water are mixed according to the target moisture content.

Step 2: the samples $(\Phi 152 \mathrm{~mm} \times h 120 \mathrm{~mm})$ are prepared using a compaction hammer with a weight of $4.5 \mathrm{~kg}$ and the diameter of $5.0 \mathrm{~cm}$. The samples are compacted in five layers, and each layer is compacted 98 times using the compaction hammer.

Step 3: the dry density of the sample prepared in Step 2 is measured.

Step 4: Steps 1-3 are repeated, and the optimum moisture content and the maximal dry density are determined.

Step 5: the final cylindrical samples are compacted to a size of $\Phi 100 \mathrm{~mm} \times h 200 \mathrm{~mm}$ using a compression testing machine using the optimum moisture content.

The maximum dry density and the optimum moisture content of different unbound granular materials are shown in Table 3. GM and LX1 stand for the samples with the strong skeleton gradation compacted by the VVCM and MPCM, respectively. GF and LX2 stand for the samples with the specification gradation compacted by the VVCM and MPCM, respectively. The strong skeleton gradation and the specification gradation can be found in Table 2 .

In addition, a sampling inspection shows that the errors of the dry density and the moisture content of the final formed samples are both less than 5\%, compared to the maximum dry density and the optimal moisture content. Hence, we consider that the samples that are finally formed
TABle 3: Physical parameters of unbound granular materials.

\begin{tabular}{lcccc}
\hline Abbr. & $\begin{array}{c}\text { Aggregate } \\
\text { gradation }\end{array}$ & $\begin{array}{c}\text { Compaction } \\
\text { method }\end{array}$ & $\begin{array}{c}\text { Maximum } \\
\text { dry density } \\
\left(\mathrm{g} / \mathrm{cm}^{3}\right)\end{array}$ & $\begin{array}{c}\text { Optimum } \\
\text { moisture } \\
\text { content }(\%)\end{array}$ \\
\hline GM & $\begin{array}{c}\text { Strong } \\
\text { skeleton } \\
\text { gradation }\end{array}$ & VVCM & 2.425 & 3.8 \\
\hline GF & $\begin{array}{c}\text { Specification } \\
\text { gradation }\end{array}$ & VVCM & 2.401 & 4.0 \\
\hline LX1 & $\begin{array}{c}\text { Strong } \\
\text { skeleton } \\
\text { gradation }\end{array}$ & MPCM & 2.390 & 4.2 \\
\hline LX2 & $\begin{array}{c}\text { Specification } \\
\text { gradation }\end{array}$ & MPCM & 2.376 & 4.4 \\
\hline
\end{tabular}

are corresponding to the maximum dry density and the optimal moisture content under the molding method.

3.3. Test Method. The repeated triaxial load test is generally considered to be the most appropriate tool for characterizing the deformation properties of unbound granular material [31]. The test apparatus MTS810 is used in this study, as shown in Figure 1.

The repeated triaxial load tests are implemented according to the Chinese specification "Test Methods of Soils for Highway Engineering (JTG E40-2007)". The samples are totally saturated and sealed with a $0.5 \mathrm{~mm}$ thick rubber membrane. It should be explained that the thickness of the rubber membrane is not assigned in the Chinese specification. According to the suggestion of ASTM D4767, the membrane thickness does not exceed $1 \%$ of the sample diameter. In this study, no membrane correction is applied because the maximum permissible thickness of the membrane is $1 \mathrm{~mm}(1 \%$ of $100 \mathrm{~mm})$. After inspecting the membrane for punctures and making it leakproof, all pipelines and valves are completely sealed and shut down to isolate the void space of the sample from outside the system during the entire experimental process.

The repeated load triaxial tests are employed under a stress-controlled mode at a loading frequency of $1 \mathrm{~Hz}$. The controlled stress, namely, the deviator stress $\sigma_{d}$, is applied in the axial direction and is constant during the experimental process. The confining pressure stress $\sigma_{c}$ (equal to the minor principal stress $\sigma_{3}$ ) is applied by pressurizing the cell water surrounding the cylindrical sample of unbound granular material. Hence, the axial stress $\sigma_{a}$ (equal to the 


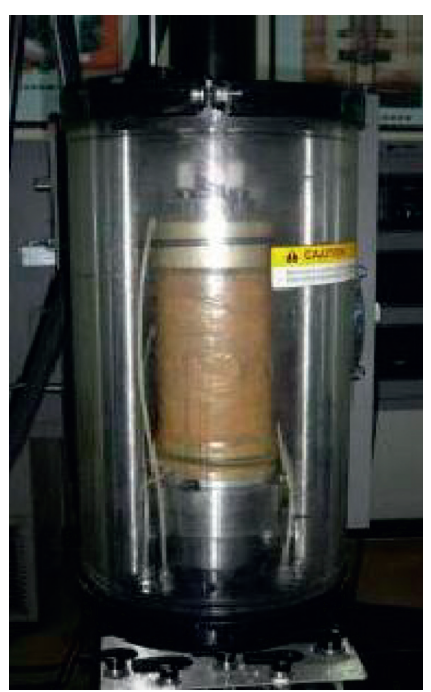

(a)

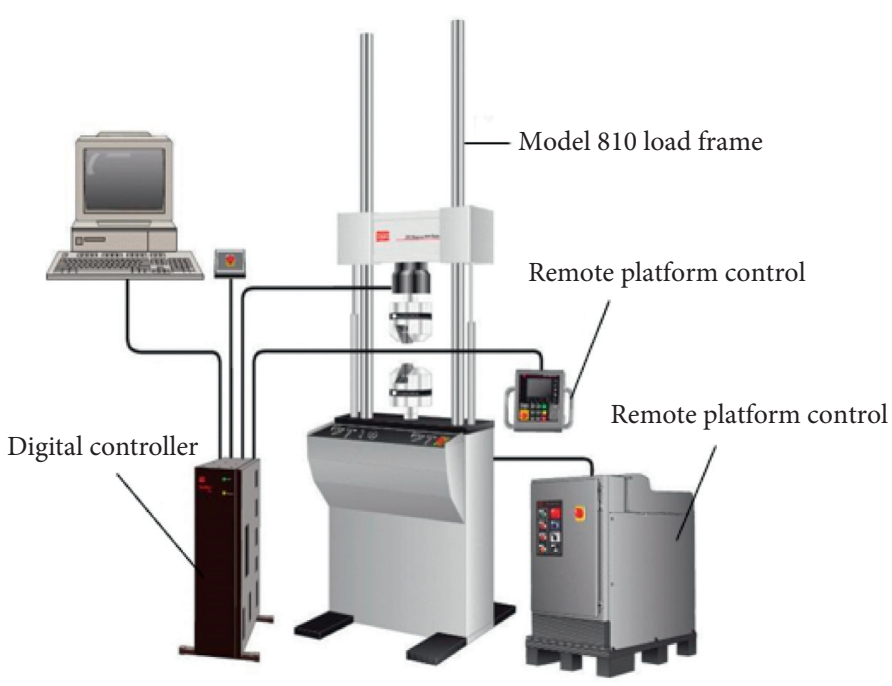

(b)

Figure 1: Repeated triaxial load test apparatus.

maximum principal stress $\sigma_{1}$ ) acting on the sample is equal to the sum of the deviator stress $\sigma_{d}$ and the confining press $\sigma_{c}$.

In this study, three types of confining stress $(50,100$, and $150 \mathrm{kPa})$ are selected because the horizontal stress of the pavement structure under loads of moving vehicles ranged, in general, from $50 \mathrm{kPa}$ to $150 \mathrm{kPa}$ [32]. The deviator stress is described via the "stress level" index, which is calculated through equation ( 1 ), of which five types $(0.1,0.3,0.5,0.7$, and 0.9) are selected. Accordingly, the relationship of $\sigma_{a}, \sigma_{d}$, and $\sigma_{c}$ can be expressed as equation (2). The detailed testing conditions for each aggregate gradation and compaction method are shown in Table 4 . There are a total of 60 groups of experiments in this study.

$$
\begin{gathered}
S=\frac{\sigma_{d}}{\sigma_{s}}, \\
\sigma_{a}=\sigma_{c}+S \sigma_{s},
\end{gathered}
$$

where $S$ is the stress level, $\sigma_{d}$ is the deviator stress, and $\sigma_{s}$ is the ultimate strength of the tested sample measured via the static triaxial test according to the Chinese specification "Test Methods of Soils for Highway Engineering (JTG E40-2007)”.

\section{Results and Discussion}

The loading number and the axial strain measured in the repeated triaxial load tests are the most important indices that characterize the deformation behaviour of unbound granular material $[25,26]$. Brown et al. $[33,34]$ and Rahman and Erlingsson [6] found that the axial strain of unbound granular material tended to be stable when the loading number reached 10000 times. Hence, the failure criterion of samples in this study was selected as follows:

(i) The loading number exceeds 10000 times, and the sample has not failed, as shown in Figure 2(a)
TABLE 4: Testing conditions.

\begin{tabular}{lcccc}
\hline $\begin{array}{l}\text { Confining } \\
\text { press } \sigma_{c}(\mathrm{kPa})\end{array}$ & $\begin{array}{c}\text { Deviator } \\
\text { stress } \sigma_{d} \\
(\mathrm{kPa})\end{array}$ & $\begin{array}{c}\text { Axial } \\
\text { stress } \sigma_{a} \\
(\mathrm{kPa})\end{array}$ & $\begin{array}{c}\text { Ultimate } \\
\text { strength } \sigma_{s} \\
(\mathrm{kPa})\end{array}$ & $\begin{array}{c}\text { Stress } \\
\text { level } S\end{array}$ \\
\hline 50 & 85 & 135 & 853 & 0.1 \\
100 & 128 & 228 & 1281 & 0.1 \\
150 & 170 & 320 & 1698 & 0.1 \\
50 & 256 & 306 & 853 & 0.3 \\
100 & 384 & 484 & 1281 & 0.3 \\
150 & 509 & 659 & 1698 & 0.3 \\
50 & 427 & 477 & 853 & 0.5 \\
100 & 641 & 741 & 1281 & 0.5 \\
150 & 849 & 999 & 1698 & 0.5 \\
50 & 597 & 647 & 853 & 0.7 \\
100 & 897 & 997 & 1281 & 0.7 \\
150 & 1189 & 1339 & 1698 & 0.7 \\
50 & 768 & 818 & 853 & 0.9 \\
100 & 1153 & 1253 & 1281 & 0.9 \\
150 & 1528 & 1678 & 1698 & 0.9 \\
\hline
\end{tabular}

(ii) The loading number does not reach 10000 times, but the sample has failed, as shown in Figure 2(b)

Accordingly, the deformation resistance can be evaluated through

(i) The permanent strain when the loading number reaches 10000 times and the sample has not failed

(ii) The ultimate loading number when the sample has failed

4.1. Effect of Compaction Methods. The relationship between the loading number and the axial strain of unbound granular material is plotted in Figure 3. The definitions of abbr. GM, GF, LX1, and LX2 can be found in Table 3.

As shown in Figure 3, the axial strain at the same loading number and the ultimate axial strain of the unbound 


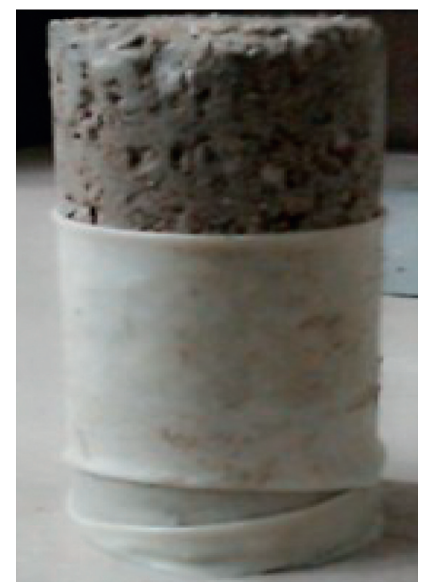

(a)

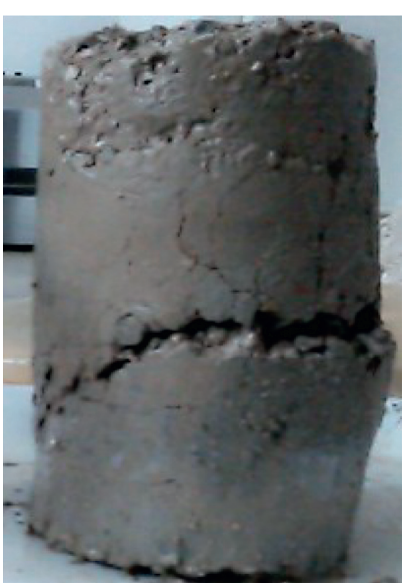

(b)

FIGURE 2: Failed sample.

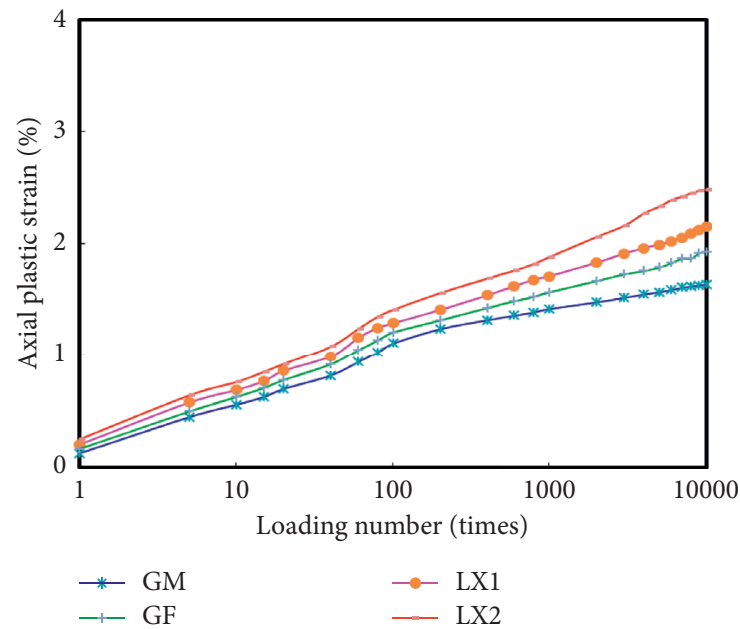

(a)

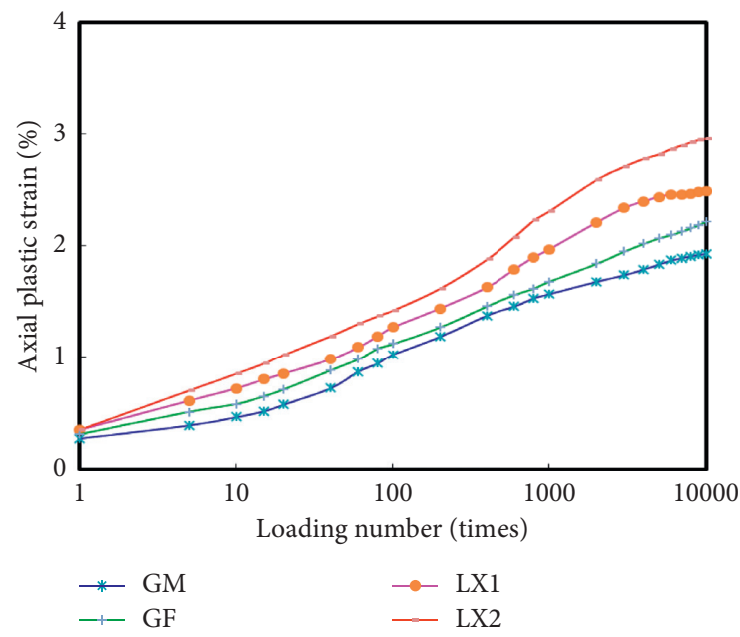

(c)

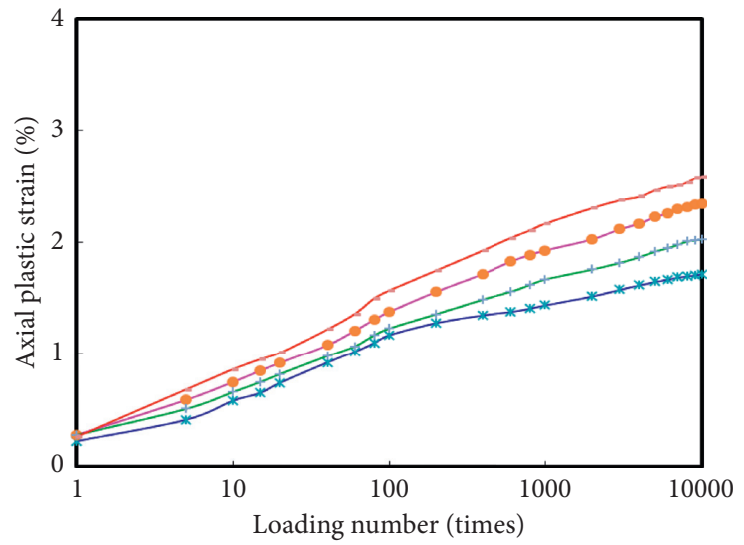

$\begin{array}{ll}* \text { * GM } & - \text { LX1 } \\ \rightarrow-\text { GF } & - \text { LX2 }\end{array}$

(b)

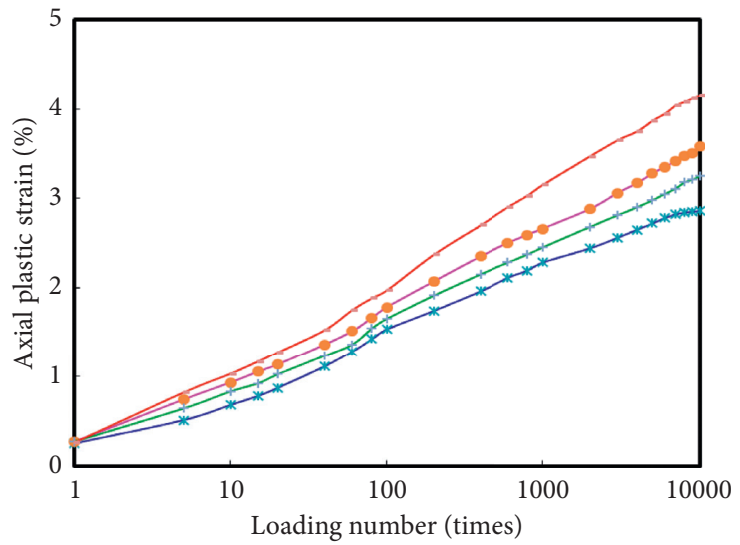

$\rightarrow$ LX1

Figure 3: Continued.

(d) 

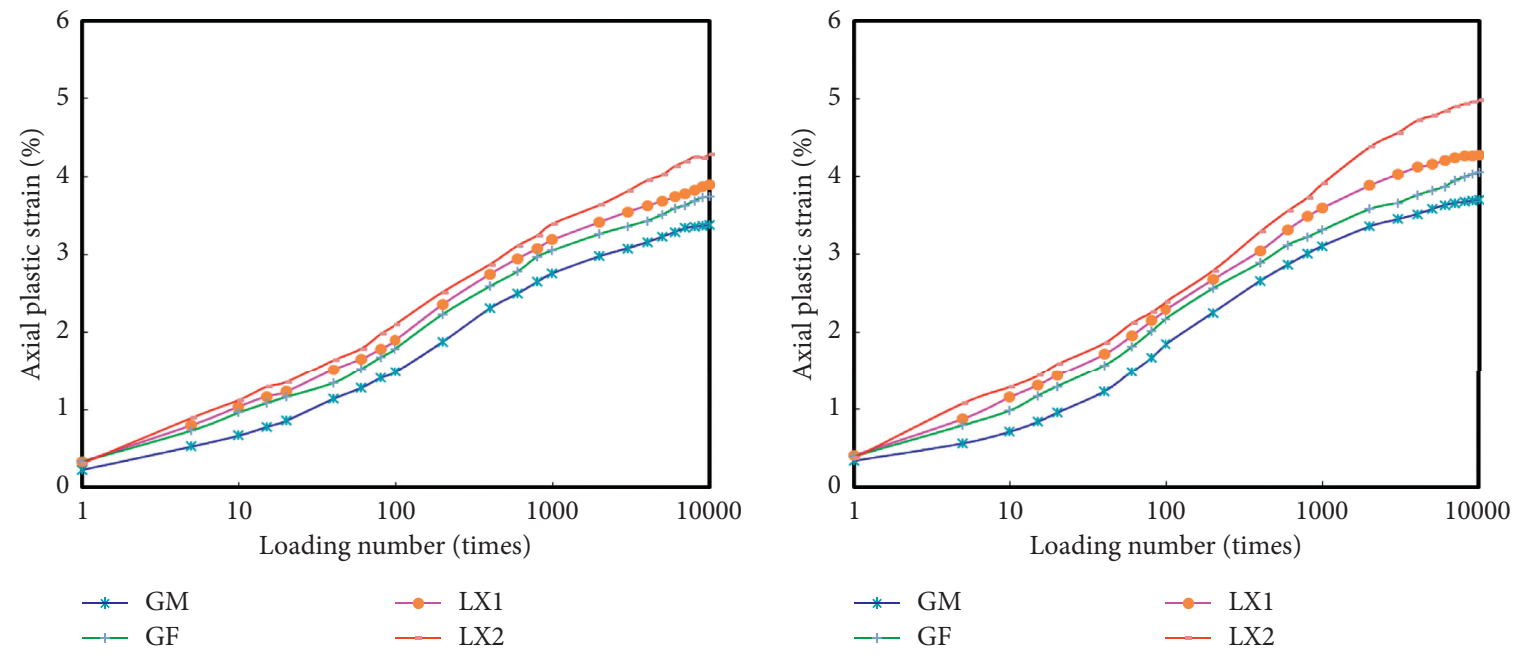

(e)

(f)
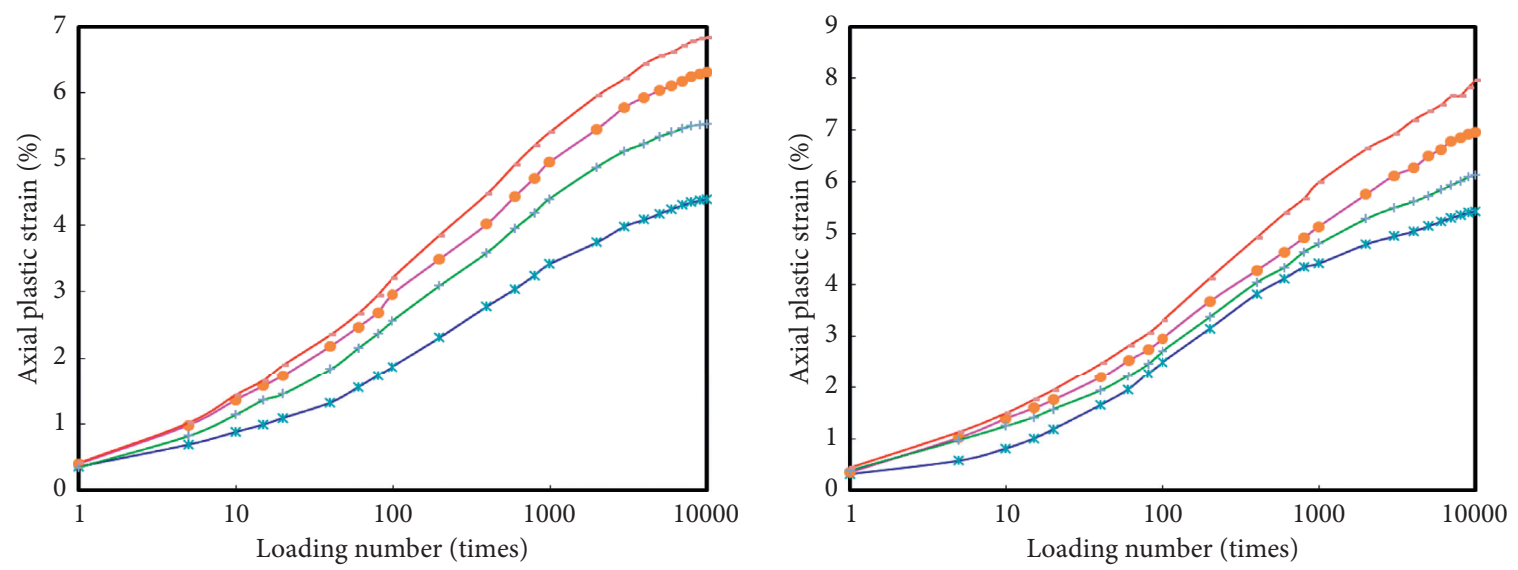

* GM

$\rightarrow$ LX1

* GM

$\rightarrow$ LX1

(g)

(h)
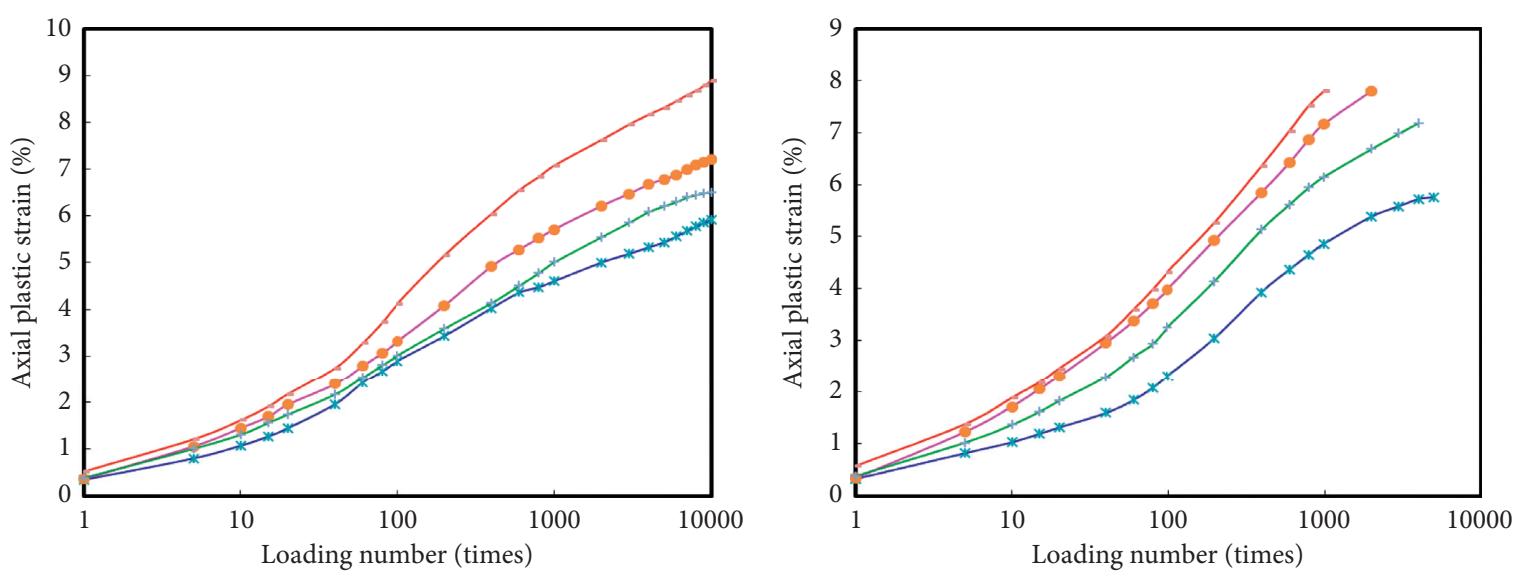

$\begin{array}{ll}\rightarrow \text { GM } & - \text { LX1 } \\ -- \text { GF } & - \text { LX2 }\end{array}$

* GM

$\longrightarrow$ LX1

(i)

(j)

FIgURE 3: Continued. 

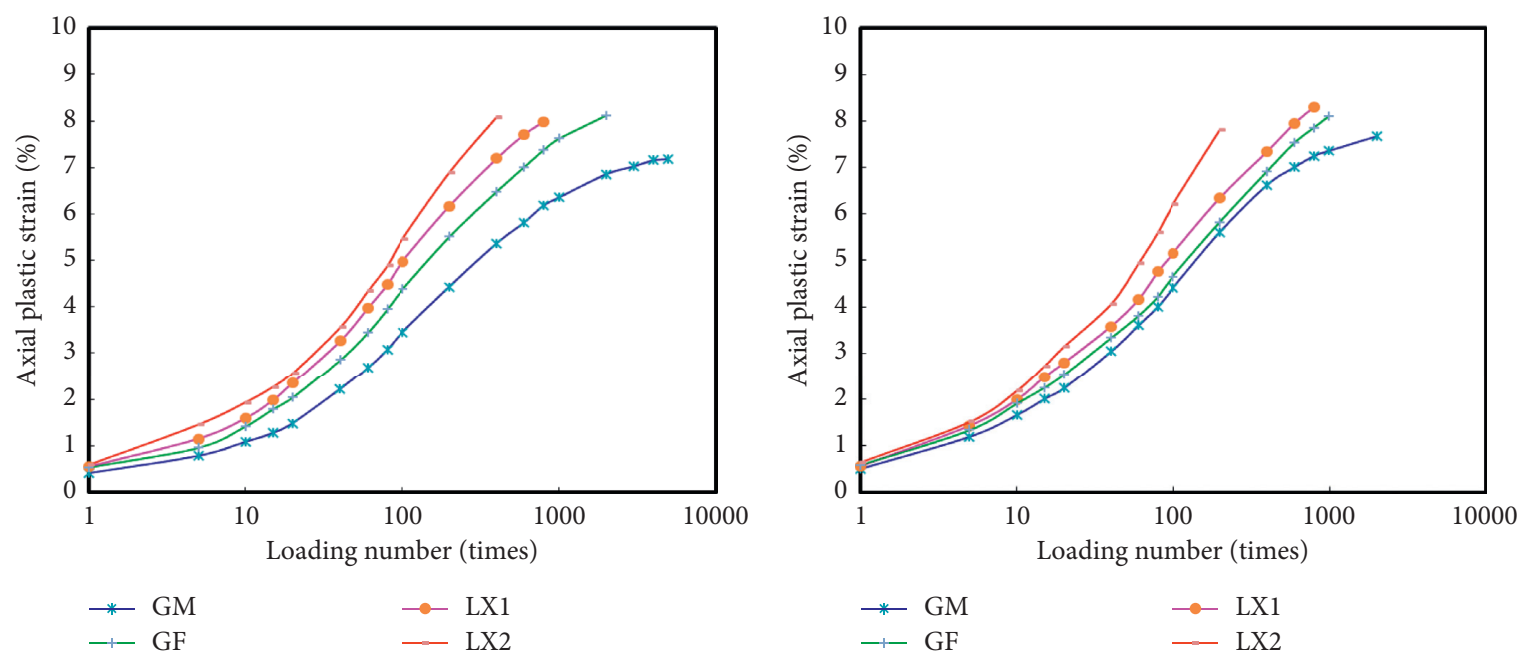

$(\mathrm{k})$

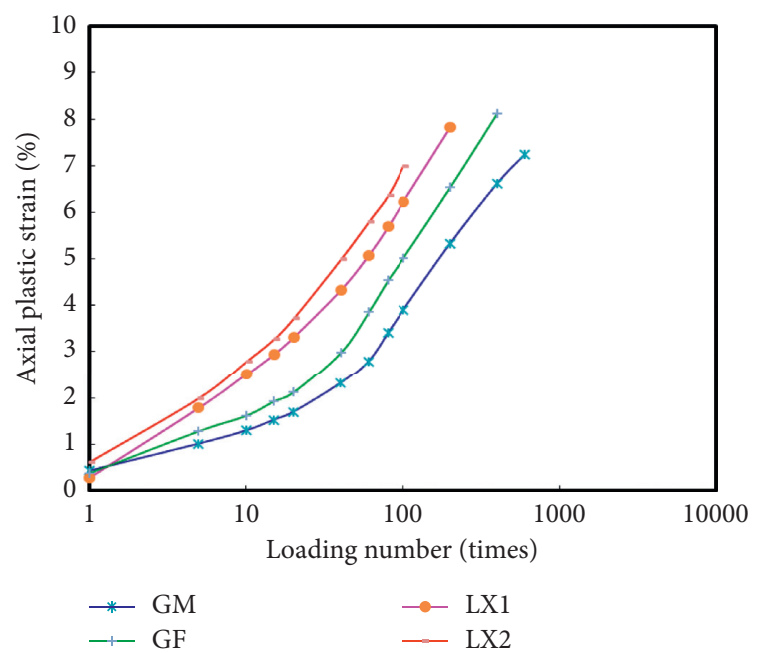

(1)

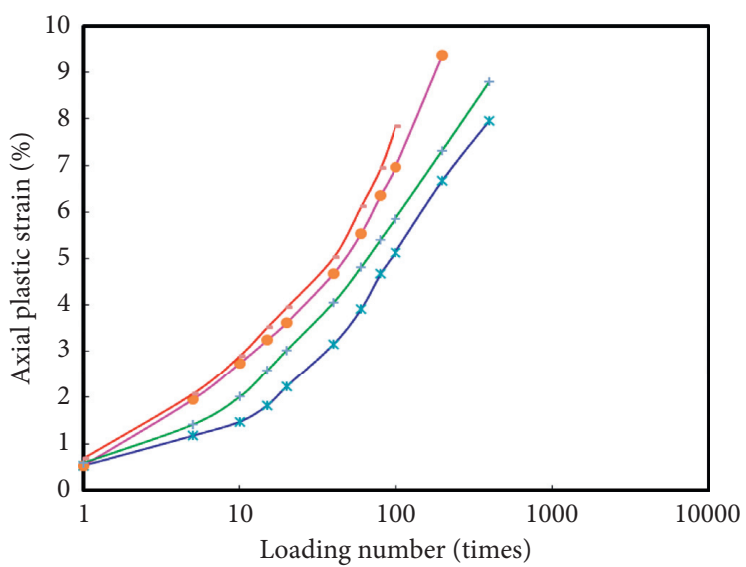

$(\mathrm{m})$

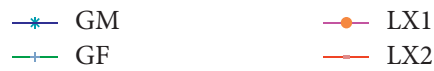

(n)

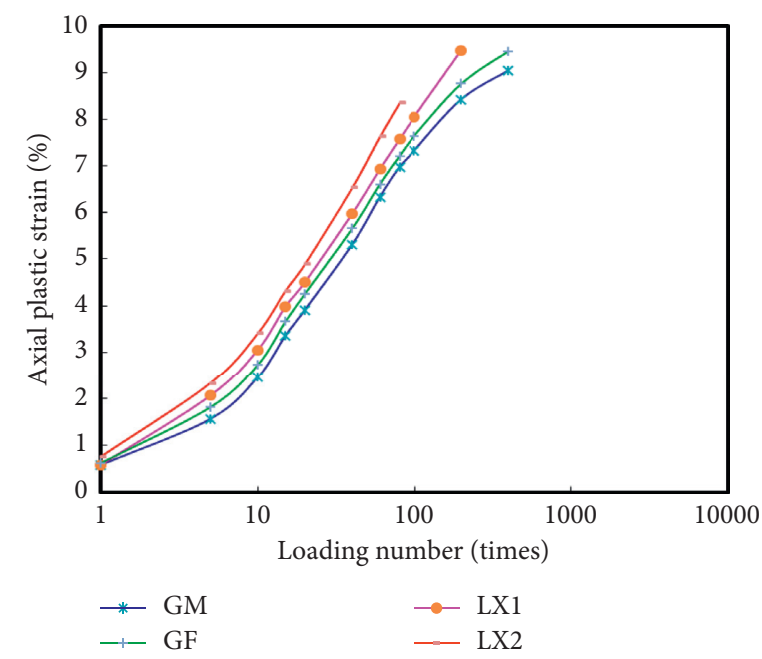

(o)

FIGURE 3: Relationship between the axial strain and loading number under different compaction methods. (a) $(\mathrm{s})=0.1, \sigma_{3}=50 \mathrm{kPa},(\mathrm{b})(\mathrm{s})=$ $0.1, \sigma_{3}=100 \mathrm{kPa},(\mathrm{c})(\mathrm{s})=0.1, \sigma_{3}=150 \mathrm{kPa},(\mathrm{d})(\mathrm{s})=0.3, \sigma_{3}=50 \mathrm{kPa},(\mathrm{e})(\mathrm{s})=0.3, \sigma_{3}=100 \mathrm{kPa},(\mathrm{f})(\mathrm{s})=0.3, \sigma_{3}=150 \mathrm{kPa},(\mathrm{g})(\mathrm{s})=0.5$, $\sigma_{3}=50 \mathrm{kPa},(\mathrm{h})(\mathrm{s})=0.5, \sigma_{3}=100 \mathrm{kPa},(\mathrm{i})(\mathrm{s})=0.5, \sigma_{3}=150 \mathrm{kPa},(\mathrm{j})(\mathrm{s})=0.7, \sigma_{3}=50 \mathrm{kP},(\mathrm{k})(\mathrm{s})=0.7, \sigma_{3}=100 \mathrm{kPa},(\mathrm{l})(\mathrm{s})=0.7, \sigma_{3}=150 \mathrm{kPa}$, (m) $(\mathrm{s})=0.9, \sigma_{3}=50 \mathrm{kPa},(\mathrm{n})(\mathrm{s})=0.9, \sigma_{3}=100 \mathrm{kPa}$, and (o) $s=0.9, \sigma_{3}=150 \mathrm{kPa}$. 
granular material produced by the VVCM under the same loading conditions are lower than those produced by the MPCM. For high stress levels, the ultimate loading number in the case of using the VVCM is higher than that in the case of using the MPCM. This implies that the VVCM results in an improved degree of deformation resistance for unbound granular material samples; the VVCM provides a higher degree of compaction energy that results in a denser aggregate structure for unbound granular material, when compared to the MPCM. However, the difference of axial strain (or the loading number for high stress levels) between the VVCM and MPCM is weaker than that between the two aggregate gradations. The ultimate axial strain of unbound granular material using the strong skeleton gradation is, on average, $20.11 \%$ lower than that using the specification gradation, whereas the difference of ultimate axial strain (or the ultimate loading number for high stress levels) between different compaction methods is, on average, $9.67 \%$.

Moreover, the difference in deformation resistance arising from using the VVCM and MPCM decreases as confining pressure increases, particularly for the strong skeleton gradation. For instance, when the stress level ranges from 0.1 to 0.5 , the differences of ultimate axial strain in the case of using the strong skeleton gradation are, on average, $18.75 \%, 11.11 \%$, and $8.72 \%$ at the confining pressure of $50 \mathrm{kPa}, 100 \mathrm{kPa}$, and $150 \mathrm{kPa}$, respectively, while those for the case of using the specification gradation are $14.16 \%$, $13.91 \%$, and $13.23 \%$, respectively. When the stress level exceeds 0.7 , a similar phenomenon also can be found, as in Figures $4(\mathrm{j})-4(\mathrm{l})$. This is because a higher confining pressure can enhance the degree of compaction of the aggregate structure, which partly compensates for the difference of compaction energy between the VVCM and MPCM. On the other hand, as previously mentioned, the most significant difference between the strong skeleton gradation and the specification gradation is that the former has a more coarse aggregate content. It also can be speculated that the sensibility of the VVCM to the deformation characteristics increases as the coarse aggregate content is increased. In addition, the stress level has less influence on the difference between deformation resistances that were observed while using different compaction methods.

4.2. Effect of Stress Levels. The relationship between the axial strain and loading number is plotted in Figure 4.

As shown in Figure 4, when the stress level ranges from 0.1 to 0.5 , the axial strain accumulates approximately linearly in the initial stages and, then, gradually tends to be stable. Although the samples are all not failed until the loading number exceeds 10000 times, the ultimate axial strain increases as the stress level is increased. When the stress level ranges from 0.7 to 0.9 , the samples fail rapidly after the loading number reaches 1000 times. The ultimate loading number also decreases as stress levels increase. This implies that the deformation resistance of unbound granular material decreases as the stress level increases. Moreover, the abovementioned law does not change significantly in accordance with the compaction method, aggregate gradation, or confining pressure. This indicates that the effect of the stress level on deformation characteristics is more significant than other factors.

4.3. Effect of Confining Pressures. The relationship between axial strain and loading numbers is plotted in Figure 5.

As shown in Figure 5, it can be found that the ultimate axial strain increases as the confining pressure is increased. This trend is obviously growing as the stress level increases. For instance, at a stress level of 0.1 , the ultimate axial strain in the case of $150 \mathrm{MPa}$ confining pressure is, on average, $12.6 \%$ higher than that in the case of $50 \mathrm{MPa}$ confining pressure, while at a stress level of 0.9 , the difference between the two confining pressures is, on average, $31.0 \%$. This implies that the effect of traffic loads on the deformation resistance of unbound granular material is highly sensitive. In addition, the difference among the three confining pressures in the case of using the strong skeleton gradation is more significant than what is observed where the specification gradation is used; this is mainly reflected in the difference of ultimate axial strain at high confining pressure. It indicates that increasing the content of coarse aggregates is conducive to enhancing the deformation resistance of unbound granular material at high levels of confining pressure.

4.4. Prediction Equation of the Deformation Behaviour for the $V V C M$. The prediction equation of the deformation behaviour provides the basis for further study on the design standards of unbound granular material [35].

Puppala et al. [36] proposed a deformation model based on the mean normal bulk stress, as shown in the following equation:

$$
\varepsilon_{a}=a_{1}\left(\frac{\sigma_{m}}{p_{a}}\right)^{a_{2}} N^{a_{3}},
$$

where $N$ is the loading number, $\varepsilon_{a}$ is the axial strain after $N$ times of repeated loading, $\sigma_{m}$ is the mean normal bulk stress, $p_{a}$ is the atmospheric pressure, and $a_{1}, a_{2}$, and $a_{3}$ are the coefficients.

Korkiala-Tanttu [37] developed the K-T model to predict the deformation behaviour, as shown in the following equation:

$$
\varepsilon_{a}=C N^{b} \frac{R}{1-R},
$$

where $N$ is the loading number, $\varepsilon_{a}$ is the axial strain after $N$ times of repeated loading, $C$ is the permanent strain in the first loading cycle, $b$ is the shear ratio parameter, and $R$ is the shear failure ratio.

Chow [38] built the UIUC model to evaluate the deformation characteristics using the deviatoric stress and shear strength ratio, as shown in the following equation:

$$
\varepsilon_{a}=a_{1} N^{a_{2}} \sigma_{d}^{a_{3}}\left(\frac{\tau_{f}}{\tau_{\max }}\right),
$$

where $N$ is the loading number, $\varepsilon_{a}$ is the axial strain after $N$ times of repeated loading, $\sigma_{d}$ is the dynamic deviator stress, 

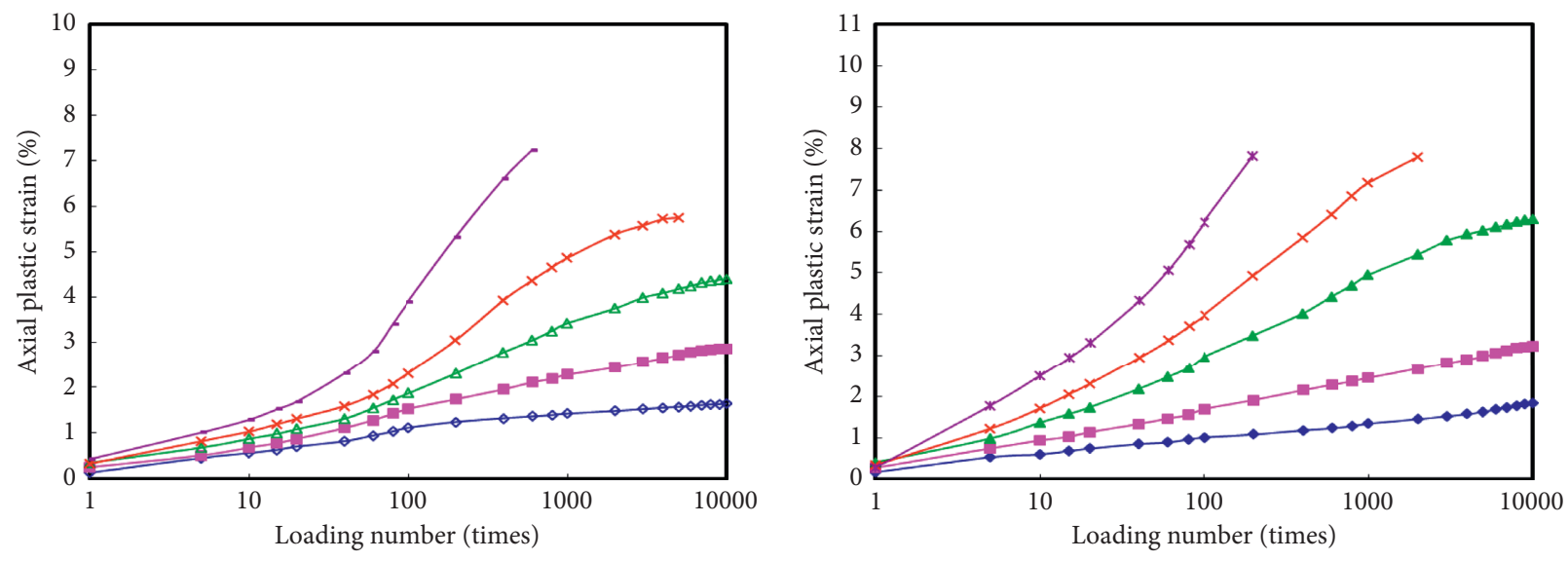

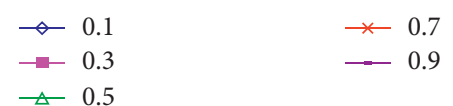

(a)

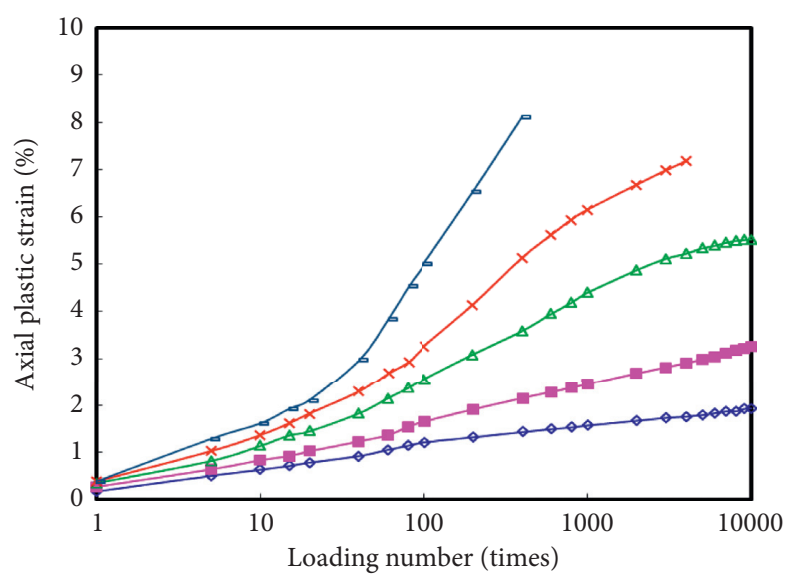

$\begin{array}{ll}\triangleleft & 0.1 \\ \rightarrow & 0.3 \\ \triangle & 0.5\end{array}$

$\rightarrow 0.7$

0.9

(c)

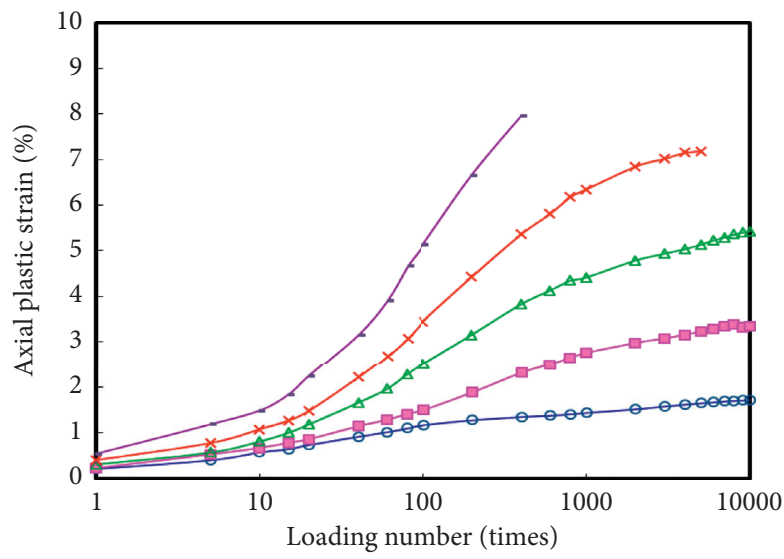

$\begin{array}{ll}\rightarrow & 0.1 \\ - & 0.3 \\ \triangle & 0.5\end{array}$ $\times \quad 0.7$
-0.9 $\rightarrow 0.1$

$\rightarrow 0.3$

$\simeq 0.5$

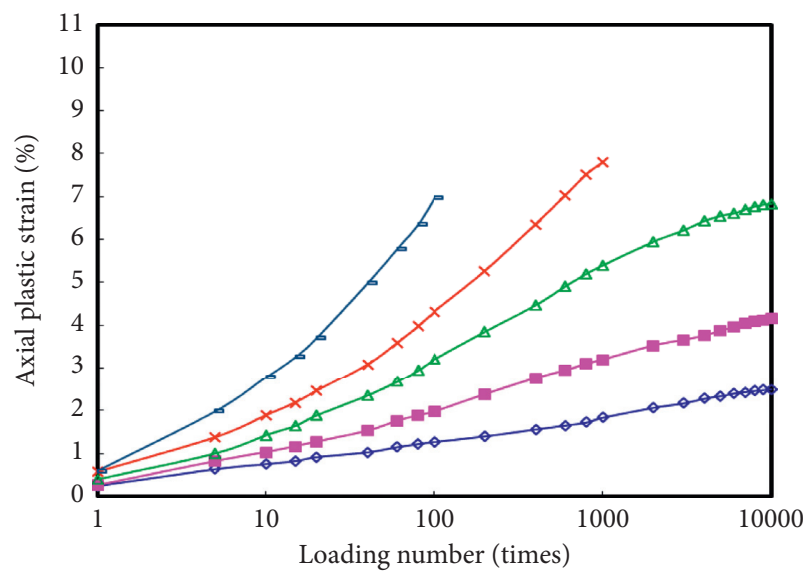

$\diamond 0.1$

$\rightarrow 0.7$

$-0.3$

$\triangle 0.5$

$\times \quad 0.7$
-0.9

* 0.9

(b)

$$
=0.9
$$

(d)

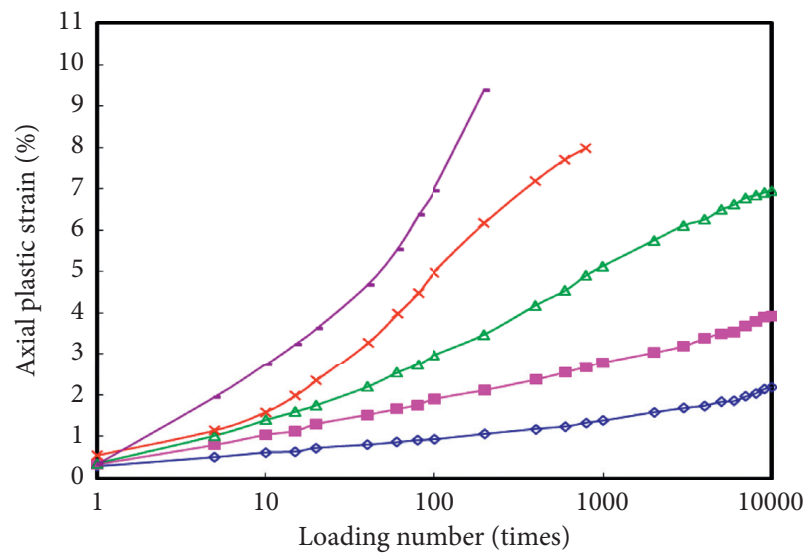

$\diamond 0.1$

$\rightarrow 0.7$

$-0.3$

$-0.9$

(e)

Figure 4: Continued. 

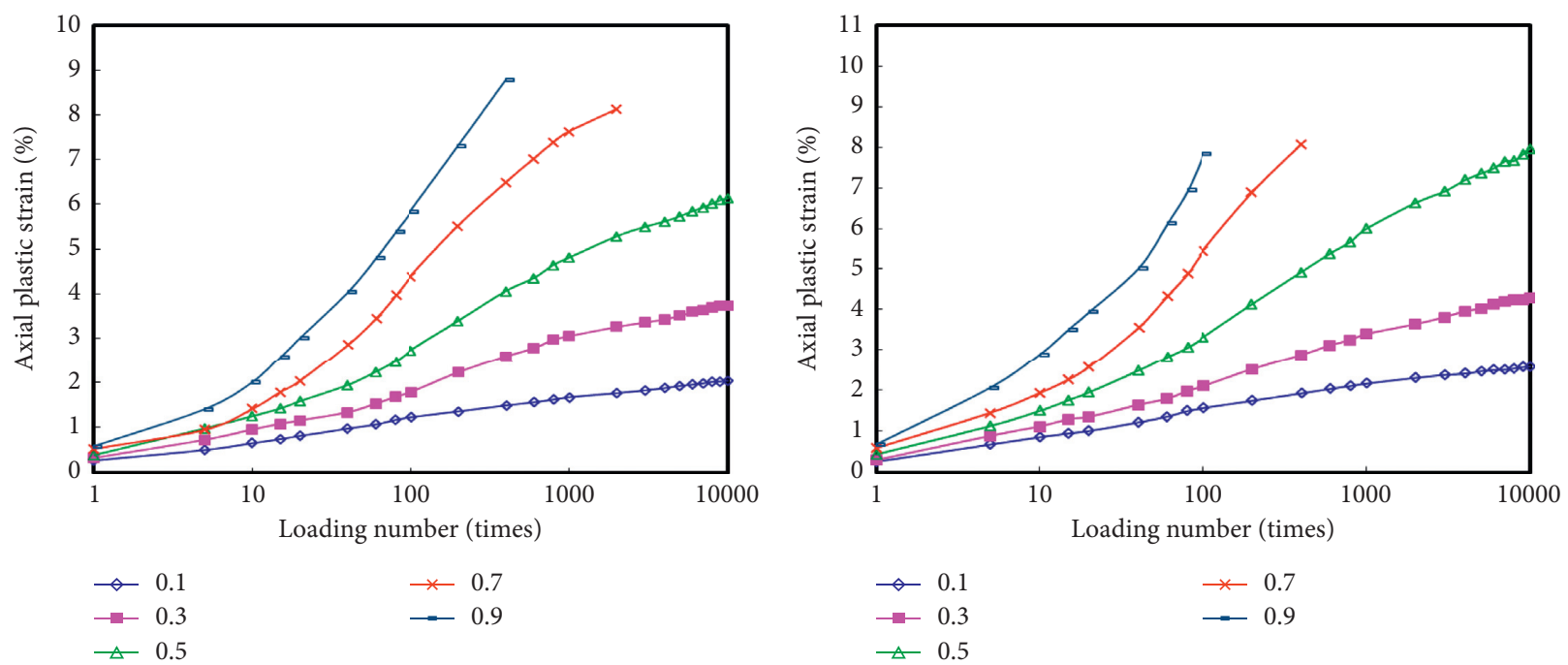

(g)

(h)
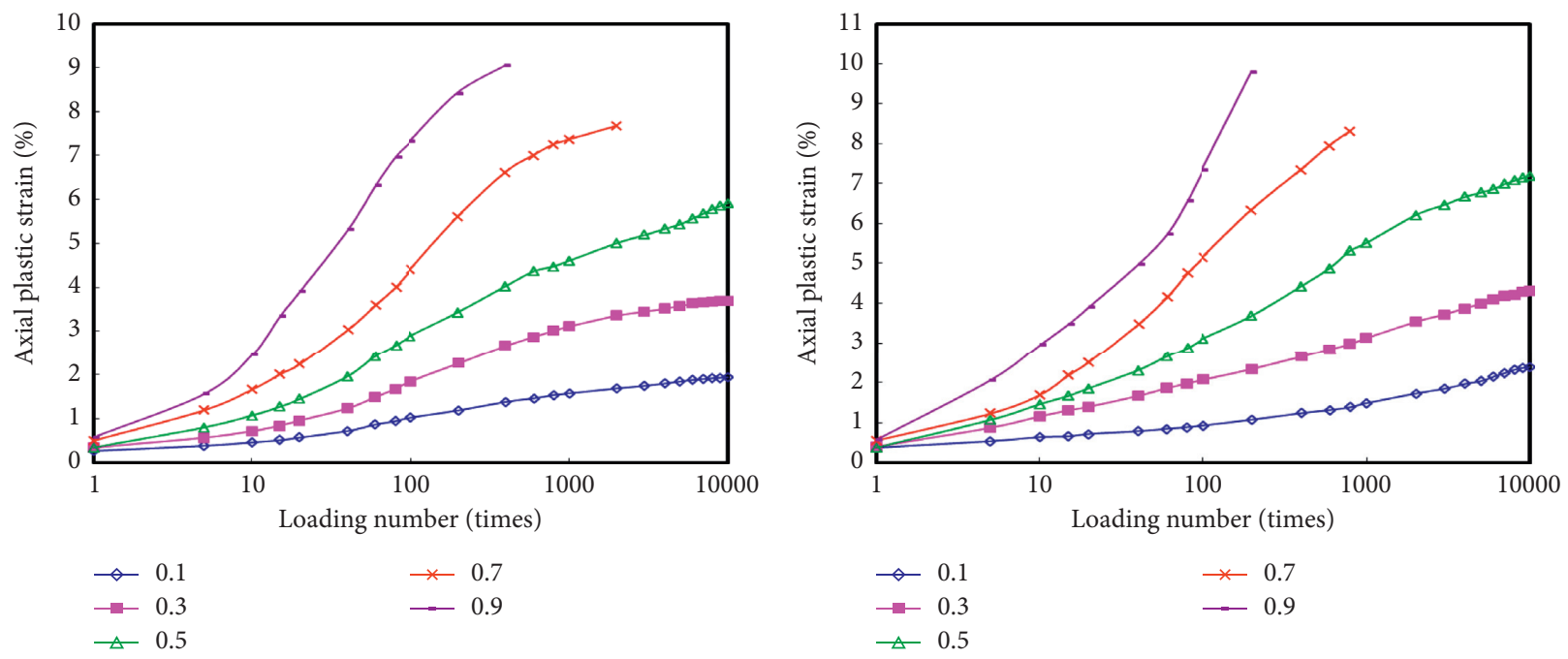

(i)
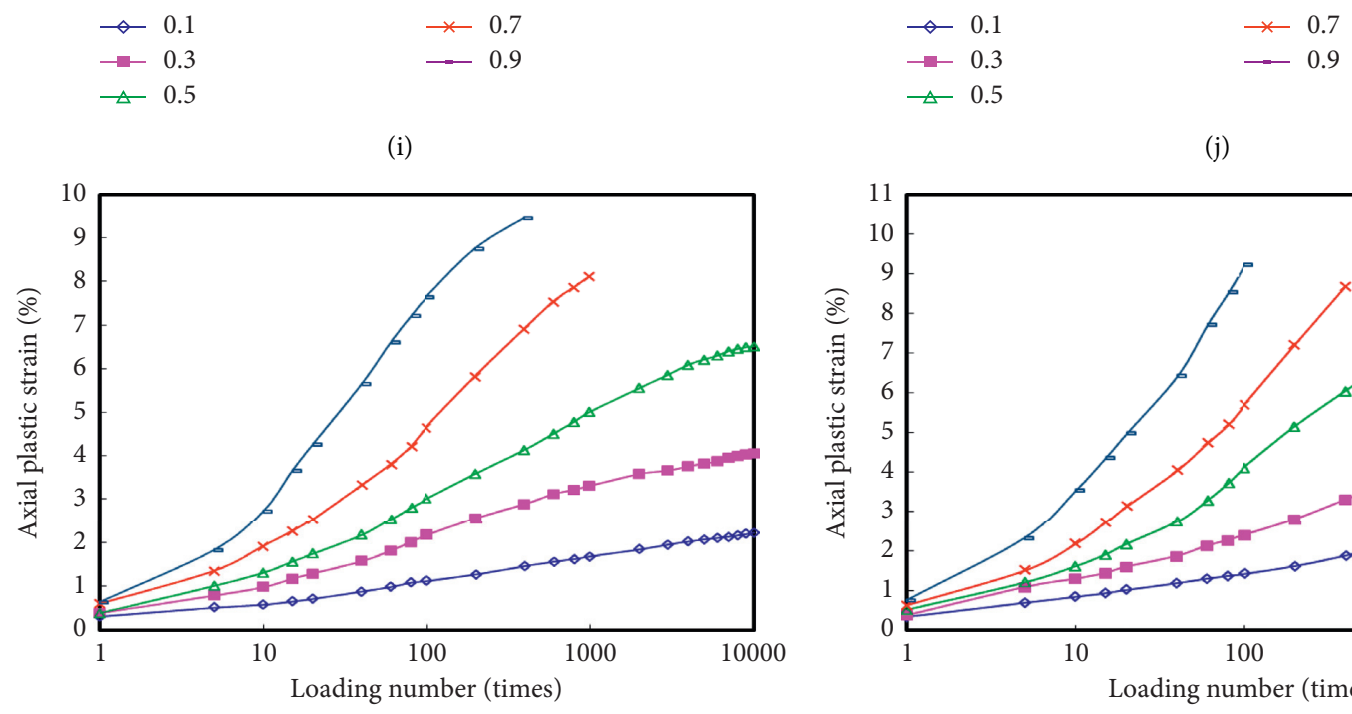

(j)

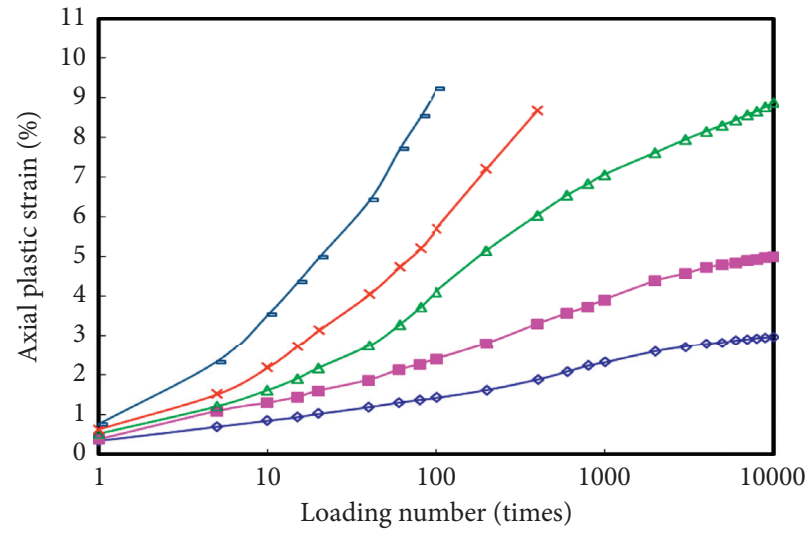

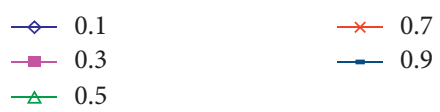

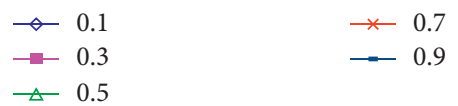

(k)

(1)

FIGURE 4: Relations between the axial strain and loading number under different stress levels. (a) $\sigma_{3}=50 \mathrm{kPa}, \mathrm{GM},(\mathrm{b}) \sigma_{3}=50 \mathrm{kPa}, \mathrm{GF},(\mathrm{c})$ $\sigma_{3}=50 \mathrm{kPa}, \mathrm{LX} 1,(\mathrm{~d}) \sigma_{3}=50 \mathrm{kPa}, \mathrm{LX} 2,(\mathrm{e}) \sigma_{3}=100 \mathrm{kPa}, \mathrm{GM},(\mathrm{f}) \sigma_{3}=100 \mathrm{kPa}, \mathrm{GF},(\mathrm{g}) \sigma_{3}=100 \mathrm{kPa}, \mathrm{LX} 1,(\mathrm{~h}) \sigma_{3}=100 \mathrm{kPa}, \mathrm{LX} 2,(\mathrm{i})$ $\sigma_{3}=150 \mathrm{kPa}, \mathrm{GM},(\mathrm{j}) \sigma_{3}=150 \mathrm{kPa}, \mathrm{GF},(\mathrm{k}) \sigma_{3}=150 \mathrm{kPa}, \mathrm{LX} 1$, and (l) $\sigma_{3}=150 \mathrm{kPa}, \mathrm{LX} 2$. 


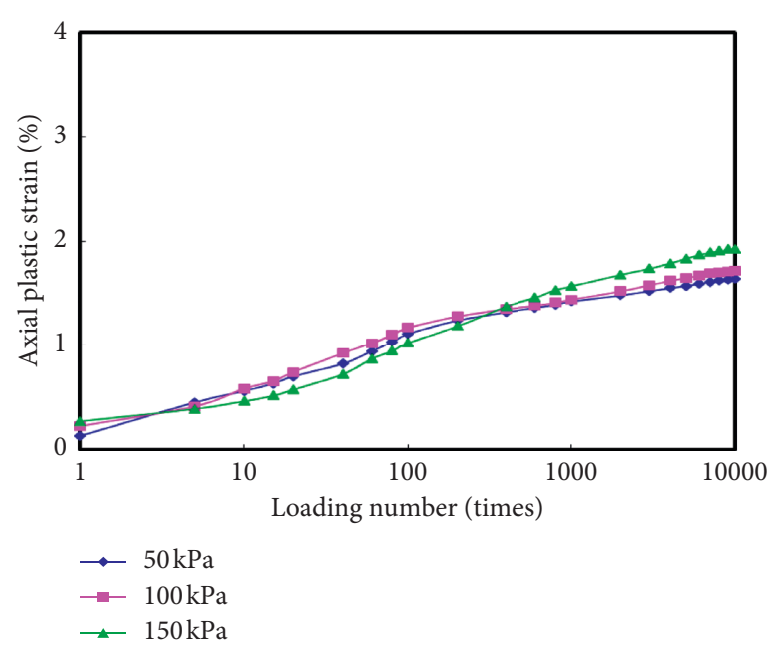

(a)

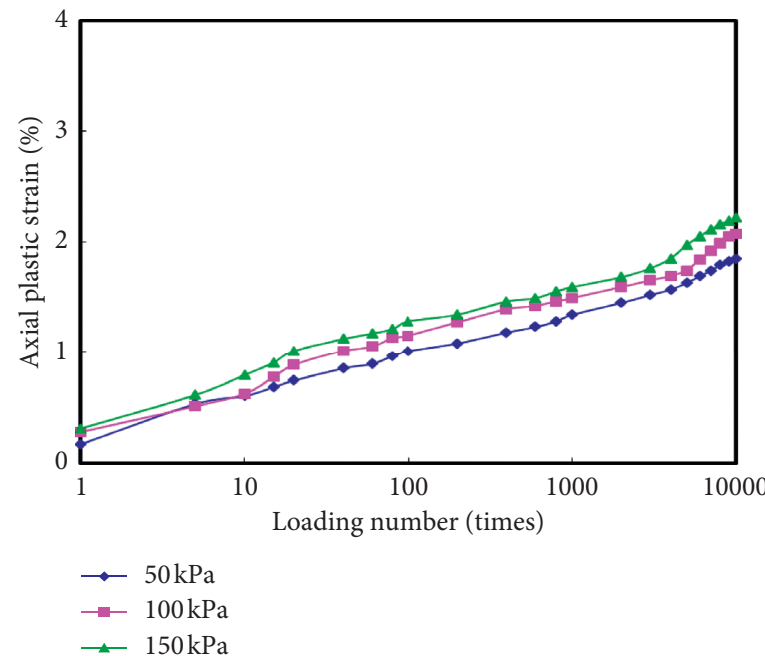

(c)

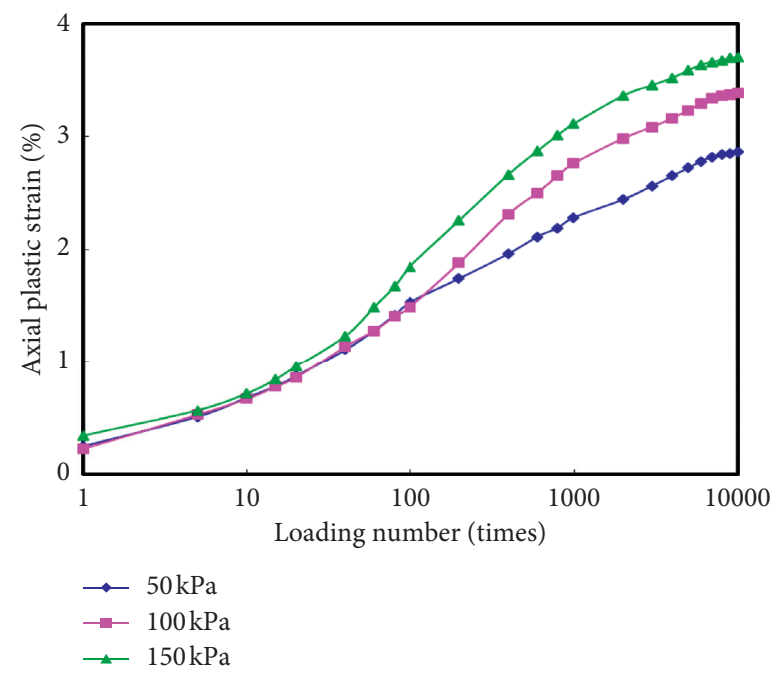

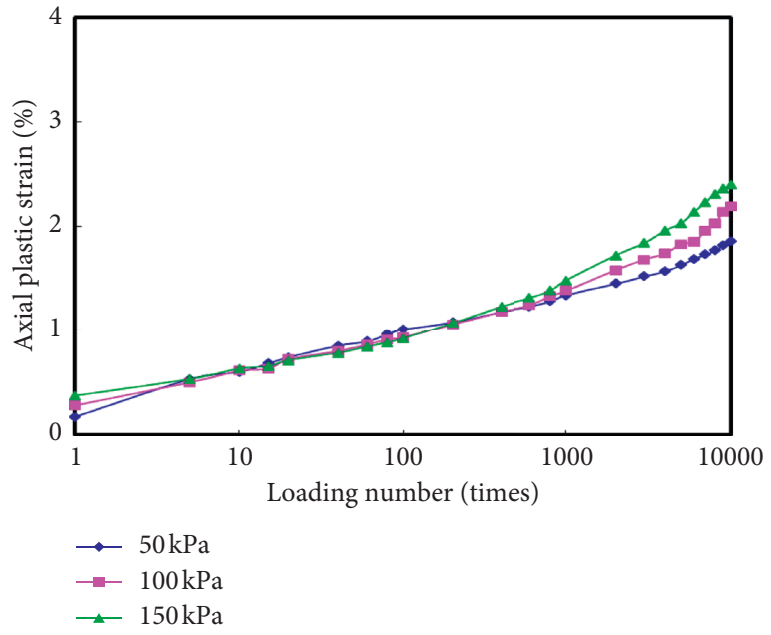

(b)

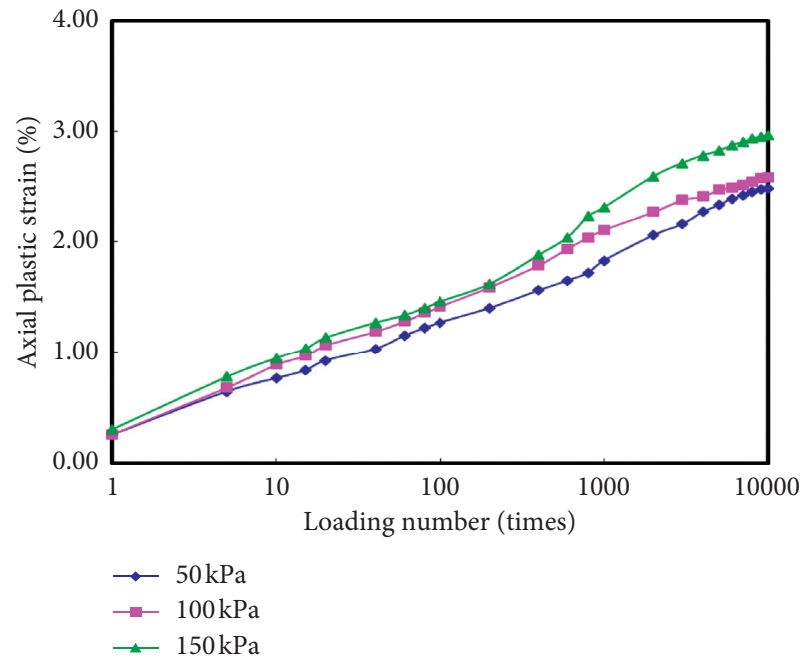

(d)

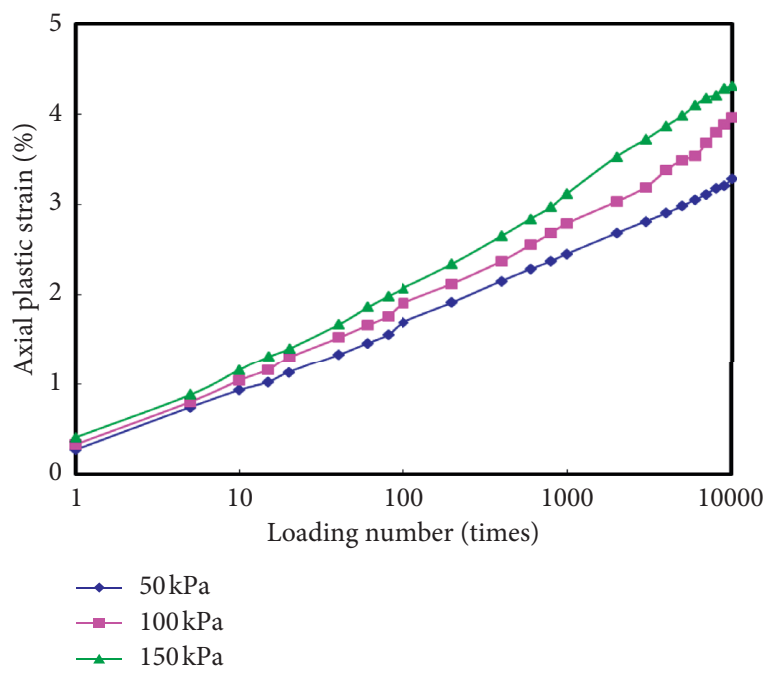

(f)

Figure 5: Continued. 

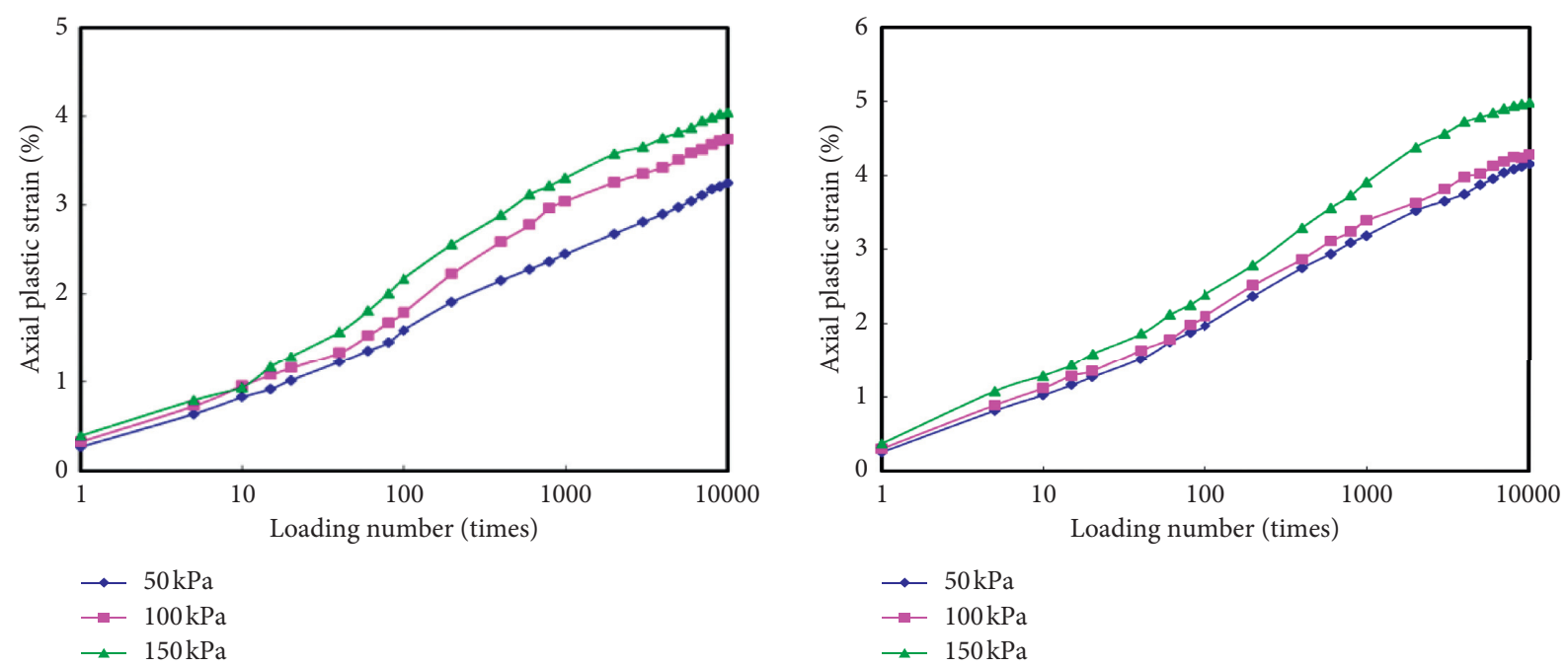

(g)
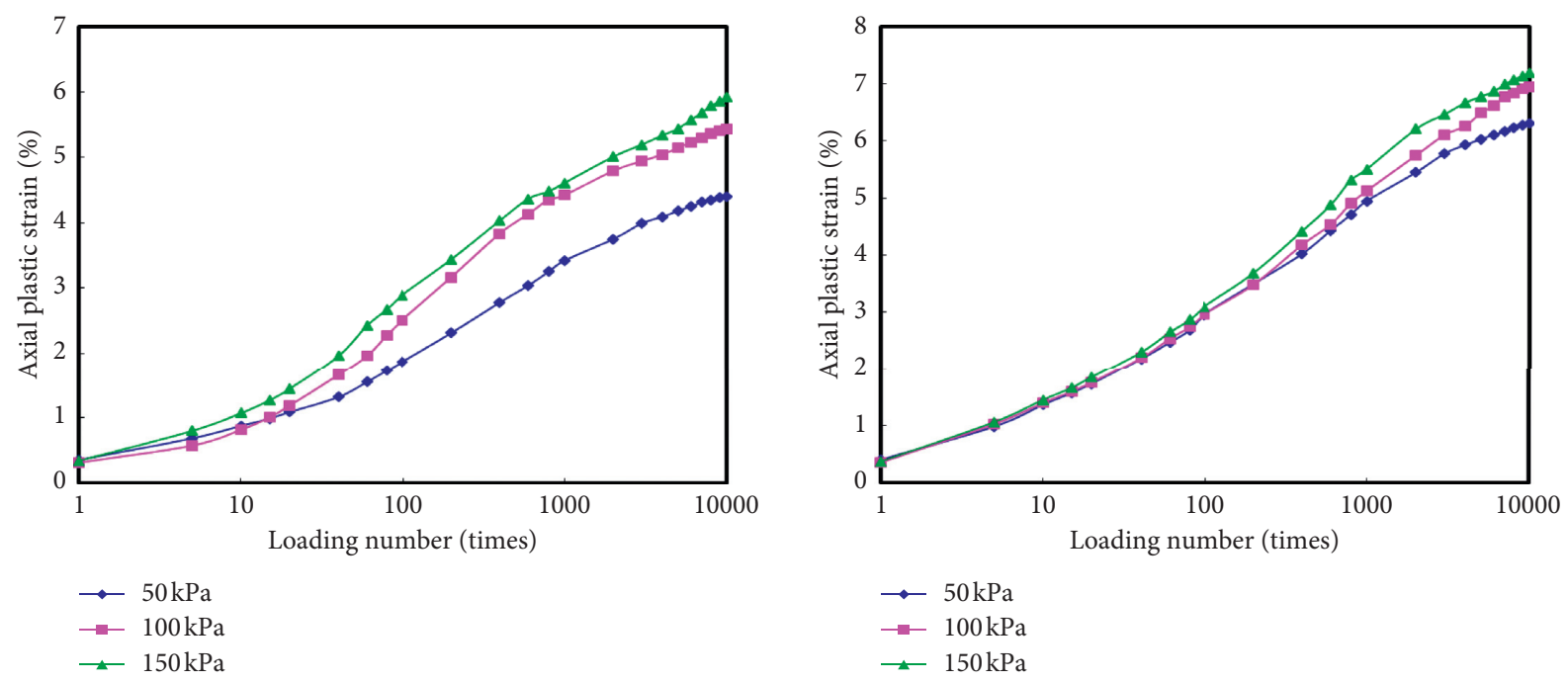

(i)

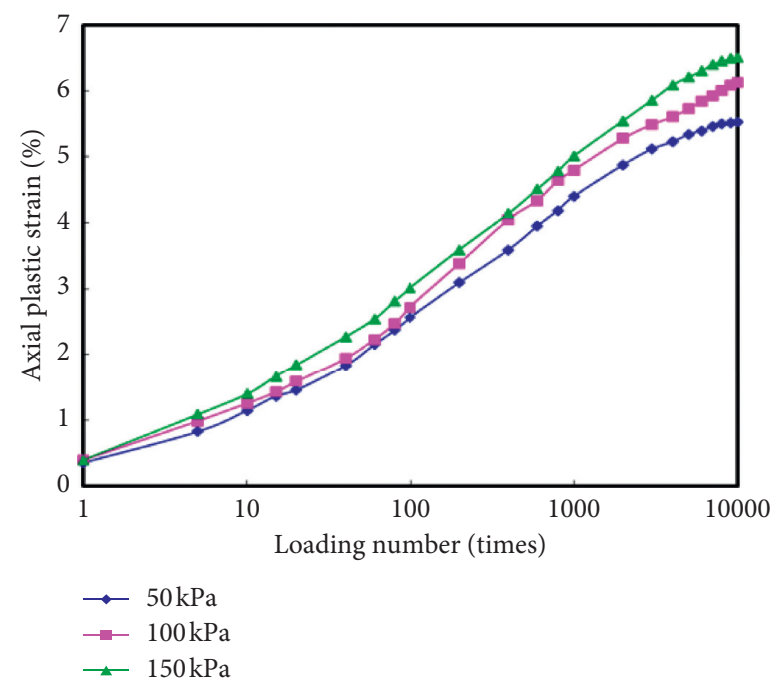

(j)

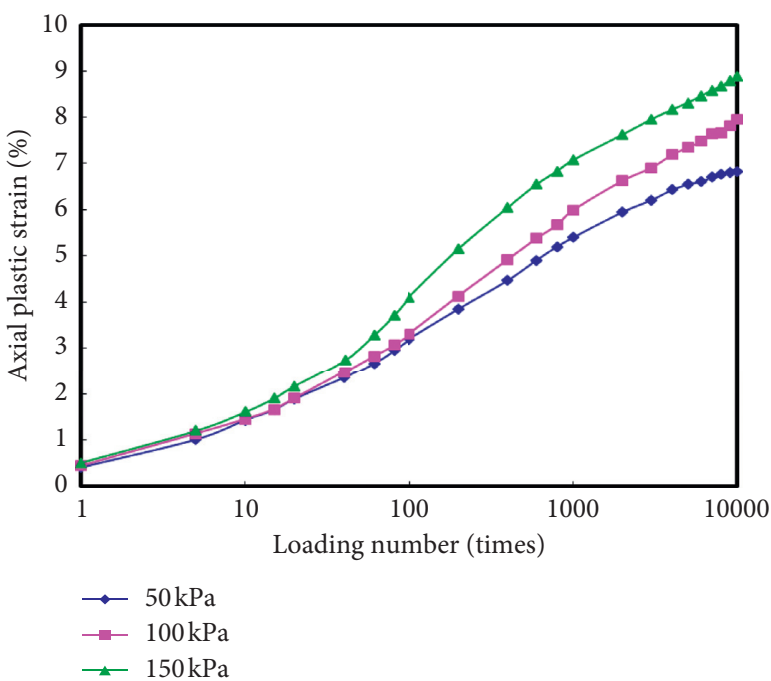

(k)

(l)

Figure 5: Continued. 


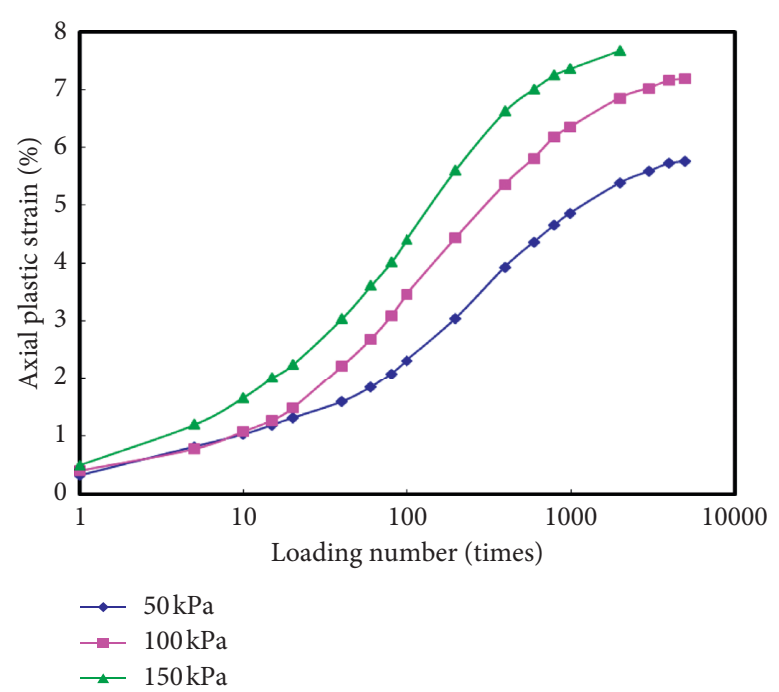

(m)

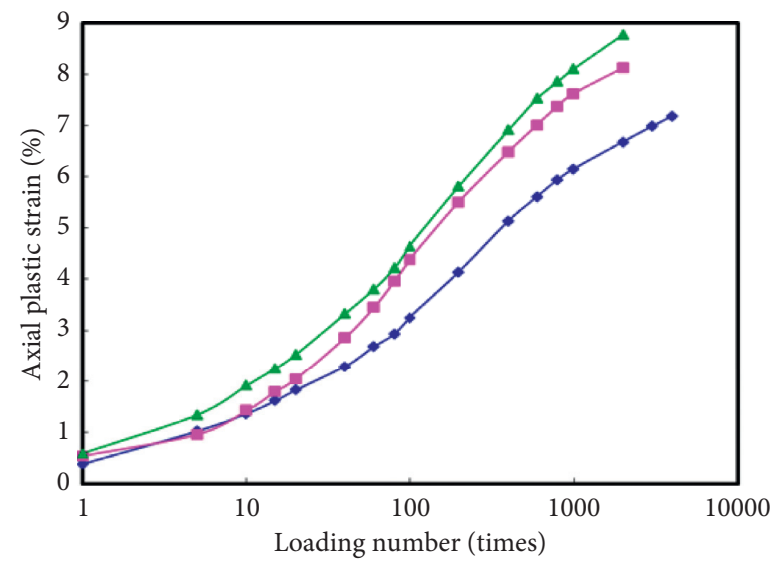

$\rightarrow 50 \mathrm{kPa}$

$\rightarrow-100 \mathrm{kPa}$

$\rightarrow 150 \mathrm{kPa}$

(o)

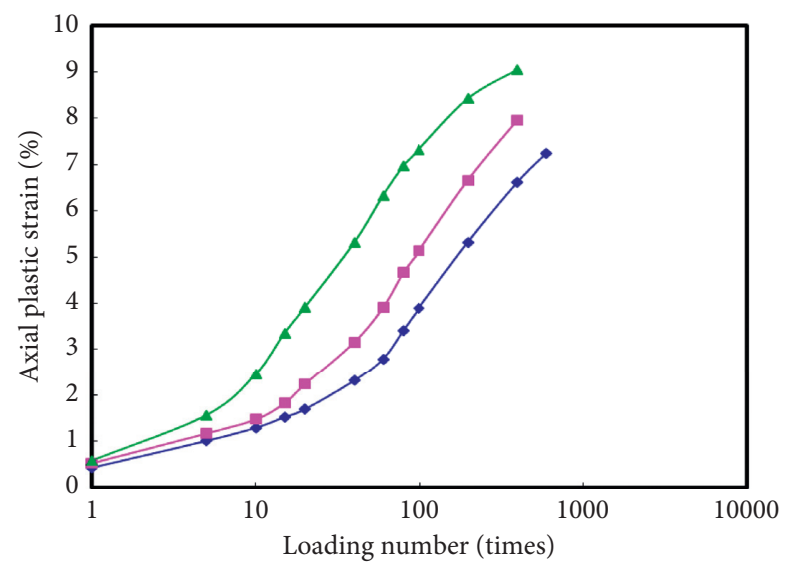

$\rightarrow 50 \mathrm{kPa}$

$\rightarrow 100 \mathrm{kPa}$

$\triangle 150 \mathrm{kPa}$

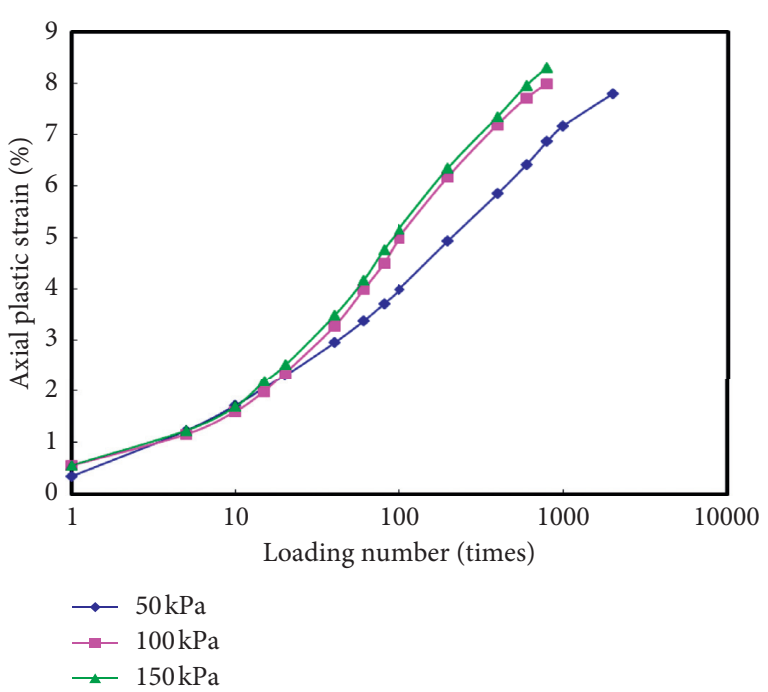

(n)

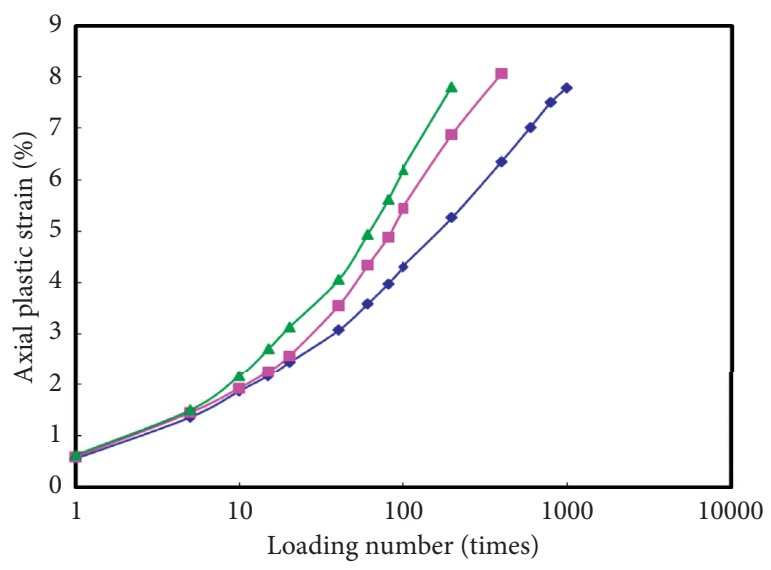

$\rightarrow 50 \mathrm{kPa}$

$\rightarrow 100 \mathrm{kPa}$

$\mp 150 \mathrm{kPa}$

(p)

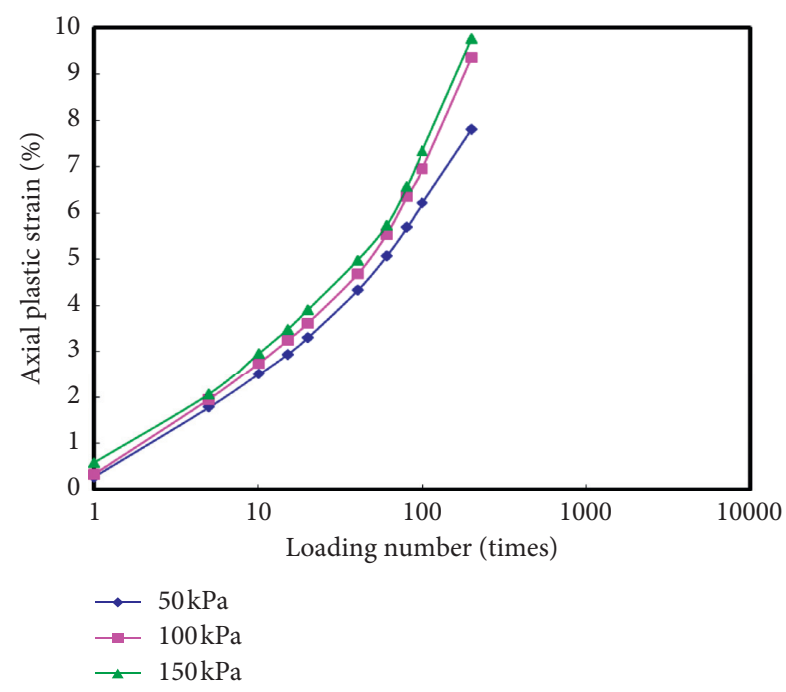

(q)

(r)

Figure 5: Continued. 


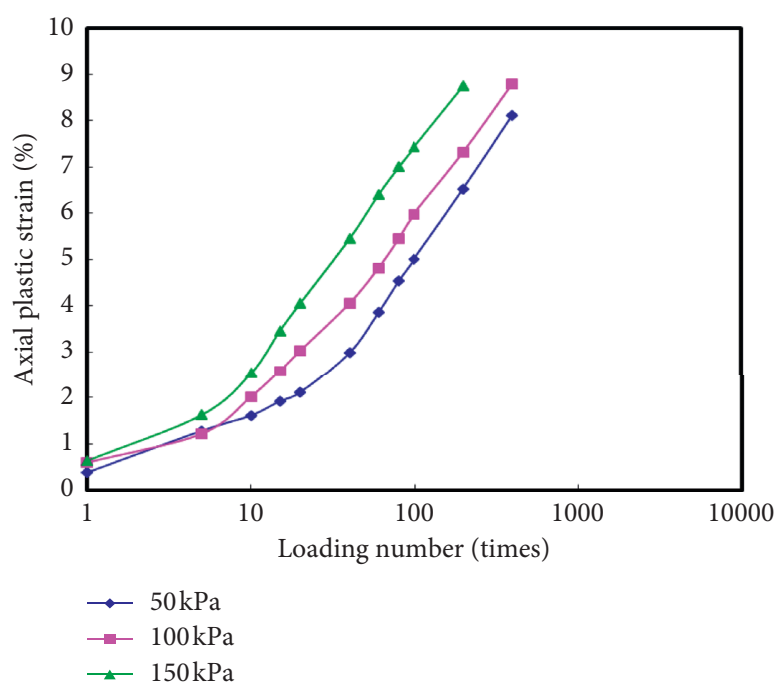

$(\mathrm{s})$

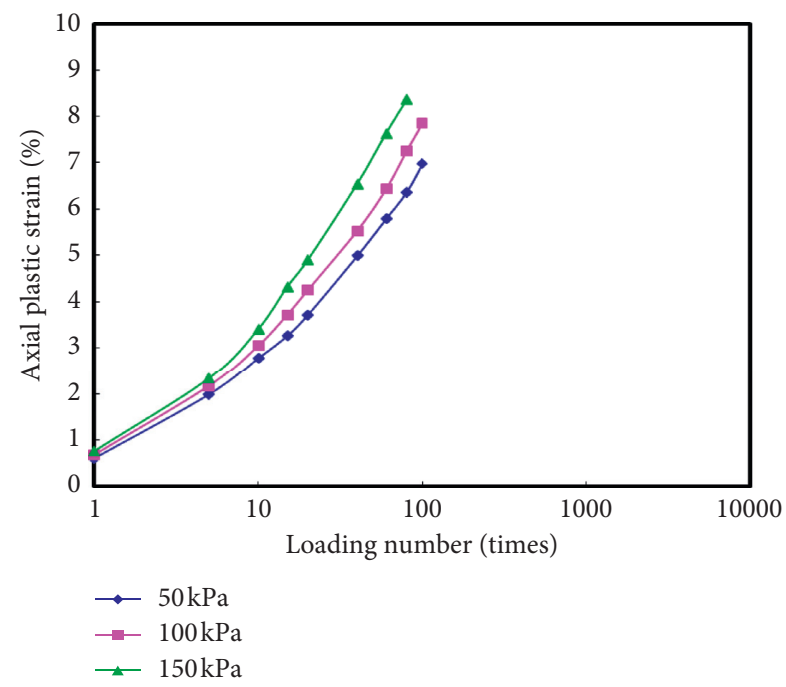

$(\mathrm{t})$

FIGURE 5: Relations between the axial strain and loading number under different confining pressures. (a) (s) =0.1, GM, (b) (s) $=0.1, \mathrm{GF},(\mathrm{c})$ $(\mathrm{s})=0.1, \mathrm{LX} 1,(\mathrm{~d})(\mathrm{s})=0.1, \mathrm{LX} 2,(\mathrm{e})(\mathrm{s})=0.3, \mathrm{GM},(\mathrm{f})(\mathrm{s})=0.3, \mathrm{GF},(\mathrm{g})(\mathrm{s})=0.3, \mathrm{LX} 1,(\mathrm{~h})(\mathrm{s})=0.3, \mathrm{LX} 2,(\mathrm{i})(\mathrm{s})=0.5, \mathrm{GM},(\mathrm{j})(\mathrm{s})=0.5, \mathrm{GF},(\mathrm{k})$ $(\mathrm{s})=0.5, \mathrm{LX} 1,(\mathrm{l})(\mathrm{s})=0.5, \mathrm{LX} 2,(\mathrm{~m})(\mathrm{s})=0.7, \mathrm{GM},(\mathrm{n})(\mathrm{s})=0.7, \mathrm{GF},(\mathrm{o})(\mathrm{s})=0.7, \mathrm{LX} 1,(\mathrm{p})(\mathrm{s})=0.7, \mathrm{LX} 2,(\mathrm{q})(\mathrm{s})=0.9, \mathrm{GM},(\mathrm{r})(\mathrm{s})=0.9, \mathrm{GF},(\mathrm{s})$ $(\mathrm{s})=0.9, \mathrm{LX} 1$, and $(\mathrm{t})(\mathrm{s})=0.9, \mathrm{LX} 2$.

TABle 5: Prediction equations.

\begin{tabular}{|c|c|c|c|}
\hline Aggregate gradation & Compaction method & Prediction equation & $R^{2}$ \\
\hline Strong skeleton gradation & VVCM & $\varepsilon_{a}=2.79 S^{0.765} \sigma_{c}^{0.255}(1-(1 /(0.21 N+1)))$ & 0.982 \\
\hline Specification gradation & VVCM & $\varepsilon_{a}=5.77 S^{0.648} \sigma_{c}^{0.117}(1-(1 /(0.38 N+1)))$ & 0.966 \\
\hline Strong skeleton gradation & MPCM & $\varepsilon_{a}=4.69 S^{0.675} \sigma_{c}^{0.151}(1-(1 /(0.35 N+1)))$ & 0.953 \\
\hline Specification gradation & MPCM & $\varepsilon_{a}=3.63 S^{0.642} \sigma_{c}^{0.249}(1-(1 /(0.40 N+1)))$ & 0.951 \\
\hline
\end{tabular}

$\tau_{f}$ is the maximum shear stress in the normal state, $\tau_{\max }$ is the maximum shear stress, and $a_{1}, a_{2}$, and $a_{3}$ are the coefficients.

Lu et al. [19] put forward the deformation equation with the deviatoric stress and static failure stress, as shown in the following equation:

$$
\varepsilon_{a}=a_{1}\left(\frac{\sigma_{d}}{\sigma_{f}}\right) N^{a_{2}}
$$

where $N$ is the loading number, $\varepsilon_{a}$ is the axial strain after $N$ times of repeated loading, $\sigma_{d}$ is the dynamic deviator stress, $\sigma_{f}$ is the static failure stress, and $a_{1}$ and $a_{2}$ are the coefficients.

Zhang et al. [23] developed an improved deformation model considering the origin octahedral shear stress, as shown in the following equation:

$$
\varepsilon_{a}=a_{1} N^{a_{2}}\left(\frac{\theta_{0}}{p_{a}}\right)^{a_{3}}\left(\frac{\tau_{\mathrm{oct}}}{p_{a}}\right)^{a_{4}}\left(\frac{\theta_{w}}{\theta_{s}}\right)^{a_{5}},
$$

where $N$ is the loading number, $\varepsilon_{a}$ is the axial strain after $N$ times of repeated loading, $\theta_{0}$ is the initial bulk stress, $p_{a}$ is the atmospheric pressure, $\tau_{\text {oct }}$ is the octahedral shear stress, $\theta_{w}$ is the volume moisture content, $\theta_{s}$ is the saturated volume moisture content, and $a_{1}-a_{5}$ are the coefficients.

In this study, the prediction equation is established according to the relationship of the axial deformation, loading number, confining stress, and stress level, which can be expressed as the following equation:

$$
\varepsilon_{a}=a_{1} S^{a_{2}} \sigma_{c}^{a_{3}}\left(1-\frac{1}{a_{4} N+1}\right),
$$

where $N$ is the loading number, $\varepsilon_{a}$ is the axial strain after $N$ times of repeated loading, $\sigma_{c}$ is the confining stress, $S$ is the stress level, and $a_{1}, a_{2}, a_{3}$, and $a_{4}$ are the coefficients.

The prediction equations for different aggregates and compaction methods are listed in Table 5.

It can be found that the correlation coefficients all have high levels $\left(R^{2} \geq 0.95\right)$, thus demonstrating the reliability of the deformation equations. Compared to the existing models, as previously mentioned, the prediction equations proposed in this study consider the relationship of the deformation, loading number, confining stress, and stress level and reflect the effect of the compaction method and aggregate gradation. It will be helpful to enrich the prediction tool of deformation behaviour of unbound granular materials. 


\section{Conclusions}

The objective of this study is to investigate the deformation behaviour of unbound granular material produced by different compaction methods and to reveal the effects of loading conditions and aggregate gradations.

(i) The deformation of unbound granular material decreases as the stress level and confining pressure are increased.

(ii) The deformation resistance of unbound granular material produced by the VVCM is superior to the MPCM.

(iii) The difference in deformation resistance resulting from using the VVCM and MPCM decreases as confining pressure is increased, particularly for the strong skeleton gradation. The effect of the stress level is not significant.

(iv) The extent that different factors affect the deformation resistance of unbound granular materials is as follows: stress level $>$ aggregate gradation $>$ compaction method $>$ confining pressure.

(v) Increasing the content of coarse aggregates is conducive to enhancing the deformation resistance of unbound granular material, particularly for the VVCM.

(vi) A simple approach for modelling the deformation prediction of unbound granular material is established.

\section{Data Availability}

The data used to support the findings of this study are included within the article.

\section{Conflicts of Interest}

The authors declare that they have no conflicts of interest.

\section{Acknowledgments}

This study was sponsored in part by the National Natural Science Foundation of China under grant no. 51808326, to which the authors are very grateful. In addition, the authors would like to thank Editage (http://www.editage.com) for English language editing.

\section{References}

[1] D. Chong and Y. Wang, "Impacts of flexible pavement design and management decisions on life cycle energy consumption and carbon footprint," The International Journal of Life Cycle Assessment, vol. 22, no. 6, pp. 952-971, 2017.

[2] S.-H. Kim, J. Yang, and J. Kwon, "Effects of using screening materials in the graded aggregate base layer of flexible pavements," International Journal of Pavement Engineering, vol. 18, no. 2, pp. 97-107, 2017.

[3] F. Varela, E. Cerro-Prada, and F. Escolano, "Preparation, characterization and modeling of unbound granular materials for road foundations," Applied Sciences, vol. 8, no. 9, p. 1548, 2018.

[4] J.-P. Bilodeau, C. O. Plamondon, and G. Doré, "Estimation of resilient modulus of unbound granular materials used as pavement base: combined effect of grain-size distribution and aggregate source frictional properties," Materials and Structures, vol. 49, no. 10, pp. 4363-4373, 2016.

[5] J. Li, J. Zheng, Y. Yao, J. Zhang, and J. Peng, "Numerical method of flexible pavement considering moisture and stress sensitivity of subgrade soils," Advances in Civil Engineering, vol. 2019, Article ID 7091210, 10 pages, 2019.

[6] M. S. Rahman and S. Erlingsson, "Moisture influence on the resilient deformation behaviour of unbound granular materials," International Journal of Pavement Engineering, vol. 17, no. 9, pp. 763-775, 2016.

[7] S. Erlingsson, "Impact of water on the response and performance of a pavement structure in an accelerated test," Road Materials and Pavement Design, vol. 11, no. 4, pp. 863-880, 2010.

[8] F. Lekarp, U. Isacsson, and A. Dawson, "State of the art. i: resilient response of unbound aggregates," Journal of Transportation Engineering, vol. 126, no. 1, pp. 66-75, 2000.

[9] F. Gu, Y. Zhang, X. Luo, H. Sahin, and R. L. Lytton, "Characterization and prediction of permanent deformation properties of unbound granular materials for pavement ME design," Construction and Building Materials, vol. 155, pp. 584-592, 2017.

[10] J. Ren and L. Sun, "Characterizing air void effect on fracture of asphalt concrete at low-temperature using discrete element method," Engineering Fracture Mechanics, vol. 170, pp. 23-43, 2017.

[11] G. Cerni, F. Cardone, A. Virgili, and S. Camilli, "Characterisation of permanent deformation behaviour of unbound granular materials under repeated triaxial loading," Construction and Building Materials, vol. 28, no. 1, pp. 79-87, 2012.

[12] Y. Xiao, K. Zheng, L. Chen, and J. Mao, "Shakedown analysis of cyclic plastic deformation characteristics of unbound granular materials under moving wheel loads," Construction and Building Materials, vol. 167, pp. 457-472, 2018.

[13] M. S. Rahman and S. Erlingsson, "A model for predicting permanent deformation of unbound granular materials," Road Materials and Pavement Design, vol. 16, no. 3, pp. 653-673, 2015.

[14] A. Alnedawi, K. P. Nepal, and R. Al-Ameri, "Effect of loading frequencies on permanent deformation of unbound granular materials," International Journal of Pavement Engineering, pp. 1-9, 2019.

[15] A. Alnedawi, K. P. Nepal, R. Al-Ameri, and M. Alabdullah, "Effect of vertical stress rest period on deformation behaviour of unbound granular materials: experimental and numerical investigations," Journal of Rock Mechanics and Geotechnical Engineering, vol. 11, no. 1, pp. 172-180, 2019.

[16] A. Alnedawi, R. Al-Ameri, and K. P. Nepal, "Neural networkbased model for prediction of permanent deformation of unbound granular materials," Journal of Rock Mechanics and Geotechnical Engineering, vol. 11, no. 6, pp. 1231-1242, 2019.

[17] A. Osouli, P. Adhikari, E. Tutumluer, and H. Shoup, "Properties of aggregate fines influencing modulus and deformation behaviour of unbound aggregates," International Journal of Pavement Engineering, pp. 1-16, 2019.

[18] G. Xu, Z. Chen, X. Li, G. Lu, D. Dong, and Z. Liu, "Establishment of control standard for plastic deformation 
performance of graded crushed stone," Construction and Building Materials, vol. 211, pp. 383-394, 2019.

[19] Z. Lu, R. Fang, Y. Zhan, and H. Yao, "Study on the dynamic deformation of road high liquid limit subgrade soil," Advances in Civil Engineering, vol. 2019, Article ID 4084983, 7 pages, 2019.

[20] M. Saberian, J. Li, and S. Setunge, "Evaluation of permanent deformation of a new pavement base and subbase containing unbound granular materials, crumb rubber and crushed glass," Journal of Cleaner Production, vol. 230, pp. 38-45, 2019.

[21] J. Zhang, J. Peng, W. Liu, and W. Lu, "Predicting resilient modulus of fine-grained subgrade soils considering relative compaction and matric suction," Road Materials and Pavement Design, pp. 1-13, 2019.

[22] J. Zhang, J. Peng, J. Zheng, L. Dai, and Y. Yao, "Prediction of resilient modulus of compacted cohesive soils in south China," Journal of Materials in Civil Engineering, vol. 19, Article ID 4019068, 7 pages, 2019.

[23] J. Zhang, J. Peng, A. Zhang, and J. Li, "Prediction of permanent deformation for subgrade soils under traffic loading in southern China," International Journal of Pavement Engineering, pp. 1-10, 2020.

[24] J. Allen, The effect of non-constant lateral pressures of the resilient response of granular materials, Ph.D. thesis, University of Illinois at Urbana-Champaign, Urbana, IL, USA, 1973.

[25] R. D. Barksdale, "Laboratory evaluation of rutting in base coarse materials," in Proceedings of 3rd International Conference on Structural Design of Asphalt Pavements, CushingMalloy, Ann Arbor, MI, USA, pp. 161-174, January 1972.

[26] L. Wang, X. Xie, and H. Luan, "Influence of laboratory compaction methods on shear performance of graded crushed stone," Journal of Materials in Civil Engineering, vol. 23, no. 10, pp. 1483-1487, 2010.

[27] A. Cetin, Z. Kaya, B. Cetin, and A. H. Aydilek, "Influence of laboratory compaction method on mechanical and hydraulic characteristics of unbound granular base materials," Road Materials and Pavement Design, vol. 15, no. 1, pp. 220-235, 2014.

[28] J. Xue and Y. Jiang, "Analysis on the fatigue properties of vertical vibration compacted lime-fly ash-stabilized macadam," Construction and Building Materials, vol. 155, pp. 531-541, 2017.

[29] E. Yaghoubi, M. M. Disfani, A. Arulrajah, and J. Kodikara, "Impact of compaction method on mechanical characteristics of unbound granular recycled materials," Road Materials \& Pavement Design, vol. 19, no. 4, pp. 1-23, 2018.

[30] D. Li and Y. Jiang, "Strong interlocked skeleton dense gradation for graded broken stones," in Proceedings of 2011 International Conference on Transportation Engineering, pp. 1630-1636, Chengdu, China, July 2011.

[31] A. A. Araya, Characterization of unbound granular materials for pavements, Ph.D. thesis, Delft University of Technology, Delft, Netherlands, 2011.

[32] M. Ameri, A. Mansourian, M. Heidary Khavas, M. R. M. Aliha, and M. R. Ayatollahi, "Cracked asphalt pavement under traffic loading-a 3D finite element analysis," Engineering Fracture Mechanics, vol. 78, no. 8, pp. 1817-1826, 2011.

[33] S. F. Brown and A. F. L. Hyde, "Significance of cyclic confining stress in repeated-load triaxial testing of granular material," Transportation Research Record, vol. 537, pp. 49-58, 1975.
[34] R. P. Elliott and M. R. Thompson, "Mechanistic analysis of AASHTO road test flexible pavements," Transportation Research Record, vol. 1043, pp. 39-49, 1985.

[35] H. Soliman and A. Shalaby, "Validation of long-term pavement performance prediction models for resilient modulus of unbound granular materials," Transportation Research Record: Journal of the Transportation Research Board, vol. 2578, no. 1, pp. 29-37, 2016.

[36] A. J. Puppala, L. N. Mohammad, and A. Allen, "Permanent deformation characterization of subgrade soils from RLT test," Journal of Materials in Civil Engineering, vol. 11, no. 4, pp. 274-282, 1999.

[37] L. Korkiala-Tanttu, "Verification of rutting calculation for unbound road materials," in Proceedings of the Institution of Civil Engineers-Transport, pp. 107-114, Thomas Telford Ltd., London, UK, May 2009.

[38] L. C. Chow, Permanent Deformation Behavior of Unbound Granular Materials and Rutting Model Development, University of Illinois at Urbana-Champaign, Urbana, IL, USA, 2014. 